\title{
DNA-cytometric grading of prostate cancer systematic review with descriptive data analysis
}

\author{
Alfred Böcking ${ }^{1 *}$, Maurits Tils ${ }^{1}$, Martin Schramm ${ }^{1}$, Josef Dietz ${ }^{2}$ and Stefan Biesterfeld ${ }^{1}$ \\ *Correspondence: alfred.boecking@web.de

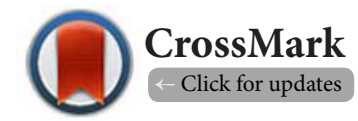 \\ ${ }^{1}$ Institute of Cytopathology, University of Düsseldorf, Germany. \\ ${ }^{2}$ Landesverband Baden Württemberg im Bundesverband Prostatakrebs Selbsthilfe, Germany.
}

\begin{abstract}
Gleason-score $<=6$, assessed on core needle biopsies, is an essential prognostic parameter to offer the strategy of Active Surveillance (AS) to patients with locally confined cancers of the prostate. Yet, its interobserver reproducibility is low (48-70\%) and its prognostic validity unsatisfactory. An option to complementary assess the malignant potential of these cancers are objective DNA-ploidy-measurements on existing biopsies. For that purpose chromosomal heterogeneity is indirectly quantified by DNA-cytometry resulting in DNA-grades of malignancy 1-4. This review systematically trawls and evaluates all scientific publications on the potential diagnostic and prognostic validity and the heterogeneity of DNA-ploidy measurements in cancers of the prostate between 1966 and 2013. Publications have been classified into Oxford levels of evidence and levels of significance were given for the correlation of DNA-ploidy with different clinical outcomes. 114 scientific articles had to be excluded because of different methodological reasons. All but one of the 67 methodologically acceptable articles report on a significant diagnostic resp. prognostic significance of DNA ploidy measurements in cancers of the prostate. 8 level $1 \mathrm{~b}$ studies report that DNA-ploidy, assessed on punch biopsies independently predicts organ confinement as assessed after radical prostatectomy. 18 level $2 \mathrm{~b}$ studies prove that DNA-ploidy measurements add statistically significant information to the Gleason-score. 16 level $2 \mathrm{~b}$ investigations report a significant correlation of DNA-ploidy with recurrence-free survival. 15 level $2 \mathrm{~b}$ studies document a significant correlation with overall survival after different types of therapy. 5 level $2 \mathrm{~b}$ investigations prove a significant correlation with local recurrence or progress after radical prostatectomy. 3 level $2 \mathrm{~b}$ publications show a significant correlation of DNAploidy with the occurrence of lymph node- or bone metastases after radical prostatectomy. 1 level $2 \mathrm{~b}$ study documents the additional prognostic value of DNA-ploidy measurements over conventional subjective grading in prostate cancer patients under AS. All existing 15 narrative reviews on selected articles dealing with prognostic DNA-cytometry in cancers of the prostate are in favor of this method. Prospective level lb studies, especially those proving the validity of DNA ploidy measurements to predict non-progression in patients with clinically insignificant low-grade low stage cancers of the prostate eligible for Active Surveillance additionally to the Gleason-score are still missing.
\end{abstract}

Keywords: DNA-cytometry, DNA-ploidy, DNA-grading, prostate cancer, Gleason-score, active surveillance, brachytherapy, prognosis

\section{Introduction}

Epidemiology

Mean age of patients facing the diagnosis of prostate cancer in Germany currently is 70 years. $26.1 \%$ of all newly diagnosed malignancies among men are cancers of the prostate. Its incidence has risen from 80 in 1993 to 111.4/100,000 men or 65,830 new cases in 2010.70,100 new cases are prognosticated for 2014. Nevertheless mortality is constantly decreasing, from 30 in 1993 to 20.0/100,000 men in 2010 [1]. Even lethality is low: $11.7 \%$ in the USA in 2006 as compared to other cancers [2]. The favorable five-years survival rate of $93 \%$ is mainly due to more frequent early diagnoses as a consequence of PSA-testing [1]. 
Böcking et al. Pathology Discovery 2014,

http://www.hoajonline.com/journals/pdf/2052-7896-2-7.pdf

doi: 10.7243/2052-7896-2-7

As about $30 \%$ of patients who, according to inquest died from prostate cancer, in fact did not according to autopsy [3], the true mortality rates may be significantly lower.

\section{Therapy}

Adequate therapy of prostate cancers essentially depends on their individual histological type, stage and grade of malignancy. High grades are associated with early and rapid tumor progression and subsequent metastasis. Low grade and low stage cancers may either locally be treated with curative intention (e.g., by radical prostatectomy, external or internal radiation) or subjected to an Active Surveillance (AS) strategy. Different to "Watchful Waiting", this includes the option for curative therapy if the cancer progresses. About $53 \%$ of all newly diagnosed patients with cancers of the prostate in Germany are currently treated by radical prostatectomy, $8 \%$ hormonally, $6 \%$ by a combination of both, $12 \%$ by radiation, $14 \%$ by AS and $5 \%$ by Watchful Waiting [4].

As the probability of patients with "clinically insignificant microcarcinomas" of the prostate [5] to die from their cancer is very low: $89 \%$ overall survival after 8 years [6], $81 \%$ overall survival after 10 years [7], the strategy of AS has been designed. About $45 \%$ of all screening-detected cancers can be managed with AS [7]. In Germany this strategy is recommended to patients with low-grade Gleason-score $(\mathrm{GS})<=6$ and low stage (T1c and T2a) cancers, found in $<=2$ core biopsies with $<50 \%$ of their volume and a PSA $<10 \mathrm{ng} / \mathrm{ml}$. It comprises regular urological examinations, repeated biopsies and PSA-controls but still allows curative therapy if clinical signs of progression can be detected [8].

\section{Shortcomings of Gleason-grading}

Grading the malignant potential of individual cancers of the prostate currently is performed according to the modified Gleason-score according to the International Society for Urologic Pathology (ISUP) [9] on histological sections of biopsies or resected tissue.

Grading the malignant potential of cancers should be reproducible among different pathologists, representative for the tumor as a whole and, most importantly, prognostically valid. Grading the malignancy of cancers of the prostate should predict outcome of patients even after different types of therapy. Neither the original [10] nor the revised GS [9] reveal sufficient inter-observer reproducibility to rely clinical decisions of the significance of radical prostatectomy vs. AS on this subjective prognostic index only. [11] report a reproducibility of $58-69 \%$, [12] of $48 \%$, [13] of $70 \%$ and [14] of $47 \%$ for the revised score.

The main cause for the revision of the Gleason-system by the International Society for Urologic Pathology (ISUP) was to enhance its representativity on punch biopsies for the tumor as a whole (as observed in radical prostatectomies). Yet, contrary to what was expected, [15] found an agreement of only $72 \%$.
Two groups furthermore demonstrated that the revised Gleason-grading could neither differentiate the survival of score 7a- and 7b- [16] or GS <=6- and GS7-patients after radical prostatectomy [17].

\section{Prognostic DNA-cytometry}

Cancers of the prostate, as all other cancers [18] reveal quite different types of chromosomal aneuploidy $[19,20]$. While malignant tumors progress, their chromosomal sets may become more and more variable, caused by genetic instability $[20,21-23]$. The resulting "chromosomal chaos" $[24,25]$ can be indirectly quantified by measuring the DNA-content of hundreds to thousands of cancer cells. These methods are called DNA-flow-cytometry $[\mathbf{2 6}, \mathbf{2 7}]$, respectively DNA-imagecytometry [28-34].

It is based on measurements of the Integrated Optical Density (IOD) of stoechiometrically and specifically DNA-stained nuclei and internal calibration with normal, diploid reference cells. Measurements of nuclei under UV-light, previously stained with DNA-specific fluorescent dyes, like DAPI, in liquids flowing through a capillary are called "DNA Flow Cytometry". Its disadvantage is that the cells are lost after analysis, thus control measurements are not possible. Furthermore cancer cells cannot be differentiated from non-epithelial cells without additional immunocytochemical markers. Measurements on Feulgen-stained nuclei [35] on glass slides, using TV-imageanalysis systems are called "DNA Image Cytometry". It has the advantage that it can repeatedly be performed on prestained and specifically restained slides on individually preclassified cells. Its performance has been highly standardized by a task force of the European Society for Analytical Cellular Pathology, ESACP $[30,32-34]$. For the purpose of grading the malignant potential of selected solid tumors, four grades of increasing malignancy have been agreed upon: peridiploid (grade 1), peritetraploid (grade 2), x-ploid (grade 3 ) and multiploid (grade 4) (Table 1 and Figure 1).

Interobserver reproducibility of prognostic DNA-histogram interpretations of prostate cancer biopsies has been reported to be $93.0 \%$ and $90.2 \%[36,37]$.

\section{Existing reviews}

14 narrative reviews have so far addressed diagnostic or prog-

Table 1. Algorithms for DNA-grading prostate cancer malignancy in four groups (Haroske et al., 1998, 2001).

\begin{tabular}{ll}
\hline DNA-grade & Definition \\
\hline 1 (Peridiploid, Type A) & One stemline at $2 \mathrm{c} \pm 10 \%$ \\
2 (Peritetraploid, Type B) & $\begin{array}{l}\text { One stemline at } 2 \mathrm{c} \pm 10 \% \text {, second stemline at } \\
4 c \pm 10 \%\end{array}$ \\
3 (X-ploid, Type C) & $\begin{array}{l}\text { One additional stemline outside } 1,8 \mathrm{c}-2,2 \mathrm{c} \text { or } \\
3,6 \mathrm{c}-4,4 \mathrm{c} \pm 10 \%\end{array}$ \\
4 (Multiploid, Type D) & $\begin{array}{l}\text { More than one stemline outside } 1,8 \mathrm{c}-2,2 \mathrm{c} \text { or } \\
3,6 \mathrm{c}-4,4 \mathrm{c} \pm 10 \%\end{array}$ \\
\hline
\end{tabular}


Böcking et al. Pathology Discovery 2014,

Figure 1. Typical DNA-histograms, corresponding Gleason-scores and tentative prognosis. Frequencies ${ }^{\star}$ from [37], prognostic DNA-categories according to [41], 2001.

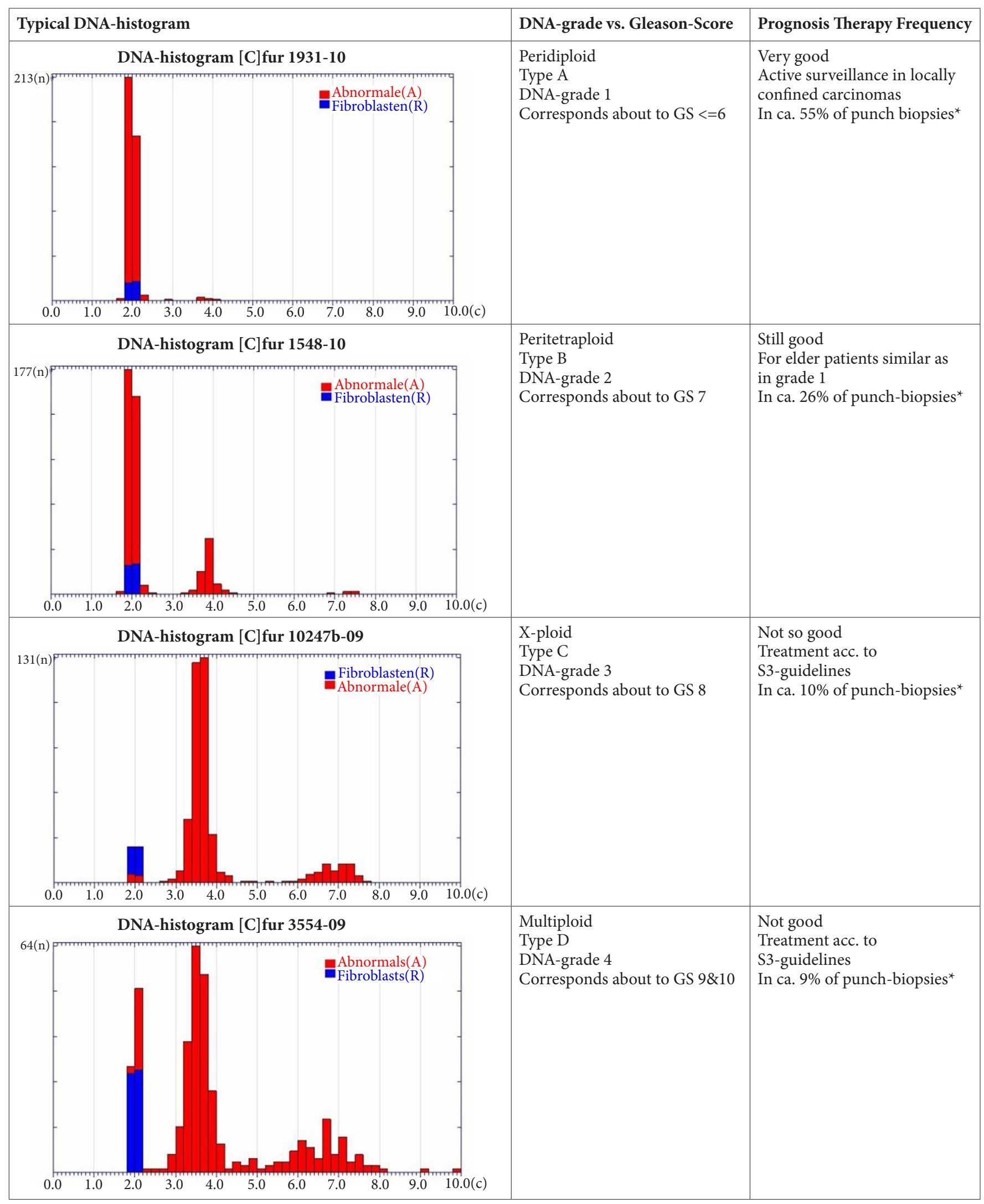


Böcking et al. Pathology Discovery 2014,

nostic DNA-cytometry in cancers of the prostate between 1992 and 2006 [38-51] Table 2. They have reviewed between 2 and 36 publications, mean 12,8. Two of them dealt with DNA-flow cytometry only [30,46]. Besides [46], who did not validate their findings, all of them concluded that this method is of diagnostic or prognostic relevance:

- "Ploidy predicts prognosis significantly" [38].

- "Ploidy looks promising following radical prostatectomy" [39].

- "DNA-ploidy is a CAP (College of American Pathologists) category II method" [40].
- "Ploidy predicts prognosis independently" [41].

- "Ploidy provides important prognostic information" [42].

- "Ploidy is a questionable independent variable" [43].

- "DNA-ploidy is a CAP category II method" [44].

- "DNA-ploidy has good potential as prognostic marker" [45].

- "It is difficult to understand why these well documented data have not yet gained access to treatment protocols" [46].

- "DNA-ploidy is of value in treatment decisions, particularly when surveillance is an option"."DNA-ploidy should uniformly be studied in clinical trials, particularly in

Table 2. Reviews dealing with DNA-cytometry in prostate cancer.

\begin{tabular}{|c|c|c|c|c|c|c|c|}
\hline Authors & Year & $\begin{array}{l}\text { Publications } \\
\text { reviewed }\end{array}$ & Systematic & $\begin{array}{l}\text { Flow/Image } \\
\text { cytometry }\end{array}$ & $\begin{array}{l}\text { Methodological } \\
\text { aspects }\end{array}$ & Prognostic significance & $\begin{array}{l}\text { Comparison } \\
\text { with other } \\
\text { markers }\end{array}$ \\
\hline Buhmeida et al., [38] & 2006 & 14 & No & FCM\&ICM & Yes & $\begin{array}{l}\text { "Predicts P significantly in organ } \\
\text { confined disease" }\end{array}$ & Yes $\mathrm{N}=7$ \\
\hline Montironi et al., [39] & 2006 & 2 & No & FCM & No & Not done & No \\
\hline Epstein et al., [40] & 2005 & 18 & No & FCM\&ICM & Yes & $\begin{array}{l}\text { "Ploidy looks promising following } \\
\text { RPE" }\end{array}$ & Yes $N=16$ \\
\hline Ross et al., [41] & 2003 & 8 & No & FCM\&ICM & No & DNA-ploidy=CAP category II & Yes $N=28$ \\
\hline $\begin{array}{l}\text { Chakravanti and Zhai et } \\
\text { al., [42] }\end{array}$ & 2003 & 8 & No & FCM\&ICM & No & Predicts P independently & Yes $N=29$ \\
\hline Mazzuchetti et al., [43] & 2002 & 8 & No & FCM\&ICM & No & $\begin{array}{l}\text { "Provides important prognostic } \\
\text { information" }\end{array}$ & Yes $\mathrm{N}=1$ \\
\hline Miller et al., [44] & 2001 & 6 & No & FCM\&ICM & No & $\begin{array}{l}\text { "Questionable independent } \\
\text { variable" }\end{array}$ & Yes $\mathrm{N}=3$ \\
\hline Bostwick et al., [45] & 2000 & 5 & No & FCM\&ICM & No & DNA-ploidy =CAP category II & Yes $\mathrm{N}=6$ \\
\hline $\begin{array}{l}\text { Sakr and Grignon et al., } \\
{[46]}\end{array}$ & 1997 & 16 & No & FCM\&ICM & No & $\begin{array}{l}\text { "Good potential as prognostic } \\
\text { marker" }\end{array}$ & Yes $\mathrm{N}=3$ \\
\hline Mikuz et al., [47] & 1997 & 4 & No & FCM\&ICM & No & $\begin{array}{l}\text { "Difficult to understand why these } \\
\text { well documented data have not } \\
\text { yet gained access to treatment } \\
\text { protocols". }\end{array}$ & No \\
\hline Schröder et al., [48] & 1994 & 36 & No & FCM\&ICM & Yes & $\begin{array}{l}\text { WHO-consensus conference: } \\
\text { "DNA-ploidy is of value in treat- } \\
\text { ment decisions, particularly when } \\
\text { surveillance is a treatment option". } \\
\text { "DNA-ploidy should uniformly be } \\
\text { studied in clinical trials, particularly } \\
\text { in patients with localized cancer". }\end{array}$ & No \\
\hline Shankey et al., [26] & 1993 & $?$ & No & FCM & Yes & $\begin{array}{l}\text { "Any sample shown to contain } \\
\text { representative tumor can provide } \\
\text { meaningful information". }\end{array}$ & \\
\hline Lieber et al., [49] & 1992 & 12 & No & FCM\&ICM & No & $\begin{array}{l}\text { "DNA-diploid tumors have a better } \\
\text { prognosis than tumors of a similar } \\
\text { stage and grade that are non- } \\
\text { diploid". }\end{array}$ & No \\
\hline Deitch et al., [50] & 1992 & 8 & No & FCM & No & $\begin{array}{l}\text { "FCM has much to tell us about } \\
\text { the natural history and biologic } \\
\text { behaviour of prostate cancer". }\end{array}$ & No \\
\hline Böcking et al., [51] & 1992 & 34 & No & FCM\&ICM & Yes & $\begin{array}{l}\text { "DNA-cytometry is a powerful tool } \\
\text { for grading the malignant potential } \\
\text { of prostatic carcinomas, superior } \\
\text { to histological and cytological } \\
\text { evaluation". }\end{array}$ & No \\
\hline
\end{tabular}


patients with localized cancer" [47].

- "In retrospective studies ... any sample shown to contain representative tumor can provide meaningful information" [48].

- "DNA-diploid tumors have a better prognosis than tu mors of a similar stage and grade that are non-diploid" [49].

- "Flow cytometry has much to tell us about the natural history and biologic behavior of prostate cancer" [50].

- "DNA-cytometry is a powerful tool for grading the malignant potential of prostatic carcinomas, superior to histological and cytological evaluation" [51].

As inclusion of patients with locally confined cancers of the prostate into the strategy of AS requires a valid prognostic assessment of individual tumors and the subjective Gleasonscore suffers from low inter-observer reproducibility and insufficient prognostic validity, more reliable prognostic biomarkers are required. So far no systematic review exists on the prognostic validity of DNA-ploidy measurements, that have to be considered to supplement the Gleason-score on identical specimens. This study provides the first systematic review on that subject.

\section{Review}

\section{Systematic review of the literature}

A query has been performed in PubMed for publications between January 1966 [52] and August 19 ${ }^{\text {th }}, 2013$ with the following key words: "prostate cancer and (DNA-ploidy or DNA-aneuploidy or DNA-cytometry or DNA-image-cytometry)". Studies were classified into different levels of evidence according to their design, applying the criteria of the Oxford Center for Evidence Based Medicine [53]:

- Level 1b, diagnosis: Validating cohort studies with good reference standards or clinical decision rule, tested within one clinical center.

- Level 2b, diagnosis: Exploratory cohort studies with good reference standard or clinical decision rule after derivation or validated on split samples or data bases.

- Level 1b, prognosis: Individual inception cohort studies with $>80 \%$ follow-up or clinical decision rule, validated in a single population.

- Level 2b, prognosis: Retrospective cohort studies or follow-up of untreated control patients in a randomized controlled clinical trial. Derivation of a clinical decision rule or validated on split samples only.

- Level 3b, prognosis: Retrospective cohort studies with insufficiently defined inclusion criteria or less than $80 \%$ of follow-up.

A. B. has performed the review. No reports were excluded because of their status of publication. A systematic assessment of publication bias had not been performed.

The following features were considered as "good reference standards": For the correlation with diagnosis, the results of histological examination of radical prostatectomies, especially concerning extracapsular spread and infiltration of seminal vesicles. For the correlation with prognosis, the recurrencefree- or overall survival time, the occurrence of lymph node- or bone metastases, clinical proof of local progression or recurrence or a so-called biochemical recurrence.

The diagnostic accuracy of specific indices of nuclear DNA distribution obtained on pretherapeutic biopsies, e.g., to render spread beyond the capsule more likely, should be compared with that of the Gleason-score in studies meeting the criteria of Oxford level of evidence $1 \mathrm{~b}$. Similarly the prognostic validity of indices of nuclear DNA-distribution should be investigated in comparison with the Gleason-Score, specific for different therapeutic settings, in Oxford level of evidence $1 \mathrm{~b}$ studies.

\section{Excluded papers}

1.819 titles had been listed and 1 found through other sources. After exclusion of 40 duplicates and reading the respective abstracts, 1.573 records have been excluded and full texts of 207 publications that seemed to deal with the above mentioned subjects were ordered and reviewed (Figure 2). 114 of these have been excluded from further evaluation due to different types of methodological shortcomings [61-174].

- 32 revealed an inadequate study design: 10 comprised < 50 patients [54-63], 6 had a mixture of different types of therapy [64-69], 5 missed sufficient therapeutic information [70-74], 3 missed sufficient follow-up information [75-77], 4 applied an inadequate gold standard (digital rectal examination, cancer volume) [78-81], 2 selected prognostically extreme groups of patients [82,83], 1 comprised mixed tumor-stages [84], 1 presented no details on recurrence [85].

- 24 correlated DNA-ploidy with non-diagnostic or prognostic features: 5 with morphometry only [86-90], 4 with changes under therapy [91-94], 1 with effects of radiation [95], 2 with stage only [96,97], 2 with cytological grade [98,99], 2 with cancer diagnosis instead of prognosis [100,101], 2 with 5a-reductase $[102,103], 1$ with PSA and Gleasonscore [104], 1 with stage and cytological grade [105], 1 with Gleason-score and stage [106], 1 with histological subtype [107], 1 with stage and non Gleason-grade [108], 1 with steroid receptors [109].

- 25 dealt with methodological aspects of cytometry only [110-134].

- 14 applied an inadequate cytometric methodology: 8 an inadequate sampling of cells [135-142], 3 performed measurements on sections of different thickness [143-145], 1 applied an inadequate internal calibration [146], 1 missed information on cytometric method [147], 1 measured only 30 nuclei per specimen [52].

- 19 various reasons: 7 were not written in English language [148-154], 3 presented case reports [155-157], 2 dealt with rat prostate cancers $[158,159], 2$ presented no own data $[160,161], 1$ correlation of biopsy and radical prostatectomy [162], 1 was redundant with a previous 


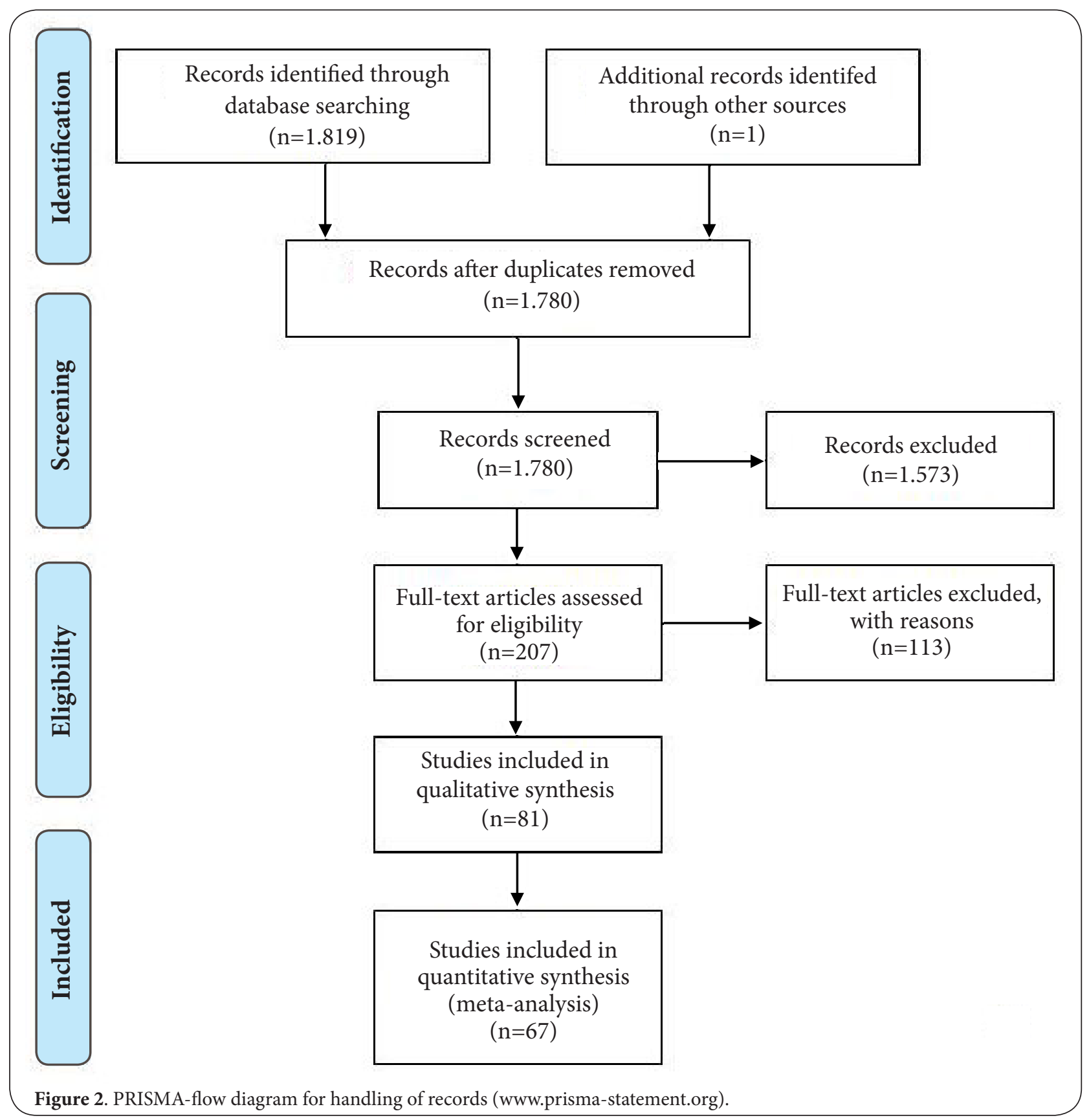

paper [163], 1 performed an inter-laboratory comparison [164], 1 compared flow- and image cytometry [165], 1 was obsolete due to a following paper [166].

\section{Methodologically sufficient papers}

Papers that did not reveal the above mentioned shortcomings were considered as "methodologically sufficient". 66 publications reported statistically significant correlations between various DNA-ploidy parameters and one of the above-mentioned patient-relevant endpoints. These comprised 15.693 patients (Tables 3-8):
- 8 level $1 \mathrm{~b}$ studies reported a significant correlation of DNAcytometric features with histologically proven cancer spread beyond the capsule as detected after radical prostatectomy [167-174]. 4 of them document a significant improvement of diagnostic accuracy concerning the prediction of organ confinement by DNA-ploidy features over Gleason-score alone (Table 3).

- 10 level $2 \mathrm{~b}$ studies were found that report on a statistically significant correlation of DNA-cytometric features with recurrence-free survival after radical prostatectomy in a multivariate-analysis $[16,175-179,181,184-186], 3$ in 
Böcking et al. Pathology Discovery 2014,

http://www.hoajonline.com/journals/pdf/2052-7896-2-7.pdf

doi: $10.7243 / 2052-7896-2-7$

Table 3. Correlation of DNA-ploidy on biopsies with extracapsular spread (ECS) after radical prostatectomy (RPE). Bold p-values refer to Cox multivariate regression analysis.

\begin{tabular}{|c|c|c|c|c|c|c|}
\hline & Year & Journal & $\begin{array}{l}\text { Number of patients } \\
\text { investigated }\end{array}$ & Months follow-up & Significance $p$ & $\begin{array}{l}\text { Flow/Image } \\
\text { cytometry }\end{array}$ \\
\hline \multicolumn{7}{|l|}{ Oxford level 1b } \\
\hline Isharwal et al., [167] & 2009 & J Urol & 370 & 5 & $\begin{array}{l}<0.001 \\
\text { AUC-ROC }+1.5 \%\end{array}$ & ICM \\
\hline Brinker et al., [168] & 1999 & J Urol & 159 & -- & 0.003 & ICM \\
\hline Vesalainen et al., [169] & 1994 & Br J Cancer & 273 & $\bar{x} 156$ & $<0.0001$ & FCM \\
\hline Ross et al., [170] & 1994 & Cancer & 89 & $\bar{x} 31.2$ & 0.04 & ICM \\
\hline Green et al., [171] & 1994 & J Urol & 70 & -- & $<0.0001$ & ICM \\
\hline Häggmann et al., [172] & 1994 & Scand J Urol Nephrol & 54 & -- & $<0.0001$ & ICM \\
\hline Ross et al., [173] & 1994 & Mod Pathol & 56 & $\bar{x} 28.8$ & 0.03 & ICM \\
\hline Badalament et al., [174] & 1991 & Cancer & 112 & -- & 0.04 & FCM \\
\hline
\end{tabular}

an univariate analysis $[180,182,183]$ Table 4. [193] found the same after external radiation in a multivariate analysis. 4 level 3b studies [187-190] proved a significant correlation of DNA-ploidy parameters with recurrence free survival time after radical prostatectomy on multivariate analyses (Table 4).

- 2 level 3b studies $[110,169]$ proved an independent correlation of DNA-ploidy parameters with overall survival time under AS apart from histological or cytological grading in a multivariate design (Table 5). 1 level 2b study did the same multivariate for recurrence free survival time [197] (Table 4).

- 6 level 2b studies proved a significant correlation of DNAploidy with overall survival after radical prostatectomy $[180,200], 2$ of them in a multivariate design $[178,198,199,201]$. 4 level 3b studies do the same [190,202,203], 1 of them univariate [204]. 6 studies provided a significant correlation of DNA-ploidy with overall survival after hormonal therapy in a multivariate design $[169,208-211,213]$. 6 level 3bstudies [85], 7 of them multivariate, showed the same [110,169,214-217]. 2 level 3b studies dealt with overall survival after AS $[43,64]$ and report a significant correlation in a multivariate analysis. [212] represents the only publication in which DNA-ploidy did not correlate with survival. But "neither Gleason-score nor WHO-grade correlated" (Table 5).

- 18 level 2b studies report that DNA-ploidy parameters add significant independent prognostic information to the Gleason-score, 12 of them after radical prostatectomy $[15,170,175-178,181,185,186,198,222,225] 2$ after hormonal therapy [199,208], 1 after external radiation [205] 1 after AS [197], 1 after brachytherapy [207] and 1 after transurethral resection [197]. 9 level 3b studies report the same after radical prostatectomy $[167,170,184$, 187,189,190,203,215,225] Table 6.

- 5 level 2b studies [170,180,182,190,225] report a significant correlation between DNA-ploidy parameters and the occurrence of local progression or recurrence after radical prostatectomy, 1 after hormonal therapy [234], 1 after brachytherapy [227] (Table 7).

- 3 level 2b [170,186,229] and 1 level 3b study [173] report on a significant correlation of DNA-ploidy parameters with the occurrence of lymph node- or bone metastases after radical prostatectomy. 2 level $3 \mathrm{~b}$ studies report the same after hormonal therapy [224,235] Table $\mathbf{8}$.

\section{Tumor heterogeneity}

The following publications dealt with aspects of heterogeneity of DNA-ploidy patterns in cancers of the prostate and representativity of punch biopsy for the tumor as a whole.

- Only 3/78 (3.8\%) diploid needle-biopsy-DNA-histograms were discrepant to those obtained on subsequent prostatectomy specimens of stages A2-B2 cancers (diploid, aneuploid), while $21.4 \%$ of biopsies had been undergraded cancers as Gleason-low-grade [170].

- 141 separate cancer foci had been investigated in 68 radical prostatectomy specimens of different stages of cancer (mean 2.1 per prostate), [39] $(n=43)$ showed hetero geneity of DNA-ploidy pattern (diploid, non-diploid) [171].

- 122 simulated punch biopsies had been investigated from nine prostatectomies containing cancers of unknown stage (mean 12 samples). Five (56\%) showed heterogeneity of the DNA pattern (diploid, tetraploid, aneuploid). All four cases having a homogenous DNA content were DNA diploid in all samples. In those cases with a heterogeneous pattern, the areas having abnormal DNA-patterns could not be predicted by histologic pattern or grade [228].

- These authors compared DNA-ploidy patterns (diploid vs. non-diploid) in punch biopsies and subsequent prostatectomy specimens in 12 cases with cancer. Four sections per resected cancer of unknown stage had been investigated. The concordance was to 92\% [230].

- Heterogeneity of DNA-ploidy patterns (diploid, tetraploid, aneuploid) had been found in $50 \%$ of $39 \mathrm{~T} 2$ and T3 cancers 
Böcking et al. Pathology Discovery 2014,

http://www.hoajonline.com/journals/pdf/2052-7896-2-7.pdf

doi: $10.7243 / 2052-7896-2-7$

Table 4. Correlation of DNA-ploidywith recurrence-free survival time. Bold p-values refer to Cox multivariate regression analysis.

\begin{tabular}{|c|c|c|c|c|c|c|c|}
\hline & Year & Journal & $\begin{array}{l}\text { Number of } \\
\text { patients }\end{array}$ & $\begin{array}{l}\text { Months } \\
\text { Follow-up }\end{array}$ & Significance $p$ & $\begin{array}{l}\text { Flow/Image } \\
\text { cytometry }\end{array}$ & Comment \\
\hline \multicolumn{8}{|l|}{ After RPE } \\
\hline \multicolumn{8}{|l|}{ Oxford level 2b } \\
\hline Bantis et al., [175] & 2009 & Tumori & 112 & $\bar{x} 60$ & 0.001 & ICM & pT2a-c, pT3a \\
\hline Pretorius et al., [16] & 2009 & Cell Oncol & 186 & $\bar{x} 73.3$ & GS $7<0.001$ & $\mathrm{ICM}$ & -- \\
\hline Bantis et al., [176] & 2005 & J Exp Clin Cancer Res & 70 & $\bar{x} 60.0$ & $<0.007$ & ICM & -- \\
\hline Deliveliotis et al., [177] & 2003 & World J Urol & 84 & $\bar{x} 45$ & 0.0074 & FCM & -- \\
\hline Amling et al., [178] & 1999 & J Urol & 106 & $\overline{\mathrm{x}} 120$ & 0.002 & FCM & After salvage prostatectomy \\
\hline Gettman et al., [179] & 1999 & Adult Urology & 211 & 60 & $<0.001$ & $\mathrm{FCM}$ & -- \\
\hline Mora et al., [180] & 1999 & Cancer Control & 65 & $\bar{x} 80$ & 0.002 & FCM & -- \\
\hline Lerner et al., [181] & 1996 & J Urol & 904 & $\overline{\mathrm{x}} 38.4$ & p 0.0089 & $\mathrm{FCM}$ & $\mathrm{pT} 1, \mathrm{pT} 2$ \\
\hline Zincke et al., [182] & 1992 & Cancer & 370 & $\bar{x} 60$ & 0.0008 & FCM & Plus hormonal treatment \\
\hline Wirth et al., [183] & 1991 & Eur Urol & 80 & 120 & 0.00013 & FCM & pT 1-3 \\
\hline Nativ et al., [184] & 1989 & Mayo Clin Proc & 146 & 94.8 & 0.006 & FCM & Stage $C \mathrm{n}=146$ \\
\hline Blute et al., [185] & 1989 & J Urol & 315 & 96 & 0.0004 & FCM & Stages A, B \\
\hline Winkler et al., [186] & 1988 & Mayo Clin Proc & 91 & $\bar{x} 90$ & 0.001 & FCM & Low and high GS \\
\hline \multicolumn{8}{|l|}{ Oxford level 3b } \\
\hline Hawkins et al., [187] & 1995 & Urology & 894 & $\overline{\mathrm{x}} 100$ & $<0.05$ & FCM & Partially HAT, \& radiation \\
\hline Carmichael et al., [188] & 1995 & J Urol & 112 & $\bar{x} 102$ & $<0.034$ & FCM & $\mathrm{T} 2, \mathrm{NO}, \mathrm{GS}<=6$ \\
\hline Voges et al., [189] & 1993 & Eur Urol & 85 & $\bar{x} 35$ & $<0.005$ & $\mathrm{FCM}$ & $<8 \mathrm{~cm} \mathrm{\&}<30 \%$ GS $4 / 5$ \\
\hline Montgomery et al., [190] & 1990 & Arch Surg & 261 & 240 & $<0.001$ & FCM & Stage B \\
\hline Lee et al., [191] & 1988 & J Urol & 88 & 60 & $<0.001$ & FCM & Interval free of disease \\
\hline \multicolumn{8}{|l|}{ Oxford level 4} \\
\hline Veltri et al., [192] & 1994 & J Cell Biochem & 124 & $\bar{x} 103.2$ & 0.008 & $\mathrm{ICM}$ & PSA-recurrence \\
\hline \multicolumn{8}{|l|}{ After external radiation } \\
\hline \multicolumn{8}{|l|}{ Oxford level 2b } \\
\hline Centeno et al., [193] & 1994 & $\begin{array}{l}\text { Int J Rad Oncol Biol } \\
\text { Phys }\end{array}$ & 70 & 136 & 0.03 & FCM & $\begin{array}{l}\text { T1-4, N0, M0 } \\
\text { S-Phase }\end{array}$ \\
\hline \multicolumn{8}{|l|}{ Oxford level 3b } \\
\hline Khoo et al., [194] & 1999 & The Prostate & 42 & $\bar{x} 62$ & 0.035 & $\mathrm{FCM}$ & -- \\
\hline Pollack et al., [195] & 1994 & Cancer & 76 & $\overline{\mathrm{X}} 40$ & 0.05 & FCM & -- \\
\hline \multicolumn{8}{|l|}{ After brachytherapy } \\
\hline \multicolumn{8}{|l|}{ Oxford level 3b } \\
\hline Peters-Gee et al., [60] & 1992 & Cancer & 51 & $\bar{x} 52$ & $<0.05$ & ICM & -- \\
\hline \multicolumn{8}{|l|}{ After hormonal therapy } \\
\hline \multicolumn{8}{|l|}{ Oxford level 2b } \\
\hline Stege et al., [196] & 1992 & J Urol & 67 & $>24$ & 0.01 & FCM & -- \\
\hline \multicolumn{8}{|l|}{ Oxford level 3b } \\
\hline Visakorpi et al., [67] & 1991 & Br J Cancer & 60 & 120 & 0.0103 & FCM & -- \\
\hline \multicolumn{8}{|l|}{ After active surveillance } \\
\hline \multicolumn{8}{|l|}{ Oxford level 2b } \\
\hline Adolfsson et al., [197] & 1990 & J Urol & 146 & $\overline{\mathrm{X}} 50$ & 0.018 & FCM & $\begin{array}{l}\text { Non-Progression. Therapy if } \\
\text { progressed }\end{array}$ \\
\hline
\end{tabular}


Böcking et al. Pathology Discovery 2014,

http://www.hoajonline.com/journals/pdf/2052-7896-2-7.pdf

doi: $10.7243 / 2052-7896-2-7$

Table 5. Correlation of DNA-ploidy with overall survival. Bold p-values refer to Cox multivariate regression analysis.

\begin{tabular}{|c|c|c|c|c|c|c|c|}
\hline Authors & Year & Journal & $\begin{array}{l}\text { Number of } \\
\text { patients }\end{array}$ & $\begin{array}{l}\text { Months } \\
\text { follow-up }\end{array}$ & $\begin{array}{l}\text { Significance } \\
\text { p }\end{array}$ & $\begin{array}{l}\text { Flow/Image } \\
\text { cytometry }\end{array}$ & Comment \\
\hline \multicolumn{8}{|l|}{ After RPE } \\
\hline \multicolumn{8}{|l|}{ Oxford level 2b } \\
\hline Ward et al., [198] & 2005 & BJU International & 816 & $\bar{x} 123.6$ & 0.008 & FCM & cT3 only \\
\hline Martinez -Jabaloyas et al., [199] & 2004 & Actas Urol Espan & 54 & $\overline{\mathrm{X}} 120$ & 0.009 & FCM & With bone marrow metastases \\
\hline Amling et al., [178] & 1999 & J Urol & 106 & $\overline{\mathrm{x}} 120$ & 0.001 & FCM & After external radiation \\
\hline Myers et al., [200] & 1997 & J Urol & 62 & $\bar{x}>120$ & 0.0014 & FCM & Plus hormonal treatment \\
\hline Di Silverio et al., [201] & 1996 & Eur Urol & 85 & $\bar{x} 35$ & 0.05 & FCM & -- \\
\hline Zincke et al., [182] & 1992 & Cancer & 370 & $\bar{x} 60$ & 0.004 & FCM & Plus hormonal treatment \\
\hline \multicolumn{8}{|l|}{ Oxford level 3b } \\
\hline Bratt et al., [202] & 1996 & Urology & 57 & $54-92$ & 0.009 & FCM & S-phase fraction \\
\hline Tinari et al., [203] & 1993 & Cancer & 63 & 84 & 0.0044 & FCM & Stages T1-T4 \\
\hline Miller et al., [204] & 1991 & J Urol & 103 & $\bar{x} 60$ & $<0.001$ & FCM & Stage D2 \\
\hline Montgomery et al., [190] & 1990 & Arch Surg & 261 & 240 & $<0.0001$ & FCM & Stage B \\
\hline \multicolumn{8}{|l|}{ After external radiation } \\
\hline \multicolumn{8}{|l|}{ Oxford level 3b } \\
\hline Pollack et al., [205] & 2003 & J Clin Oncol & 149 & $\bar{x} 96$ & 0.05 & ICM & \\
\hline Song et al., [206] & 1992 & J Urol & 65 & $>120$ & 0.0001 & $\mathrm{ICM}$ & Cancer cause specific survival \\
\hline \multicolumn{8}{|l|}{ After brachytherapy } \\
\hline \multicolumn{8}{|l|}{ Oxford level 2b } \\
\hline Stephenson et al., [207] & 1987 & Cancer Res & 82 & $60-180$ & 0.0109 & FCM & D1, N1, measured on lymphnodes \\
\hline \multicolumn{8}{|l|}{ After hormonal therapy } \\
\hline \multicolumn{8}{|l|}{ Oxford level 2b } \\
\hline Martinez-Jablonayas et al., [208] & 2002 & Urology & 127 & $>120$ & 0.031 & FCM & \\
\hline Pollack et al., [209] & 1997 & Prostate & 33 & $\bar{x} 45$ & 0.008 & FCM & \\
\hline Ahlgren et al., [210] & 1997 & Urology & 96 & $\bar{x} 176$ & 0.004 & ICM & \\
\hline Forsslund et al., [211] & 1996 & Cancer & 334 & 360 & 0.001 & ICM & \\
\hline Jörgensen et al., [212] & 1995 & Brit J Cancer & 59 & 36 & n. s. & ICM & $\begin{array}{l}\text { Neither GS nor WHO-grade } \\
\text { correlated }\end{array}$ \\
\hline Vesalainen et al., [169] & 1994 & Brit J Cancer & 273 & $\overline{\mathrm{x}} 156$ & 0.058 & FCM & T1-2, M0 \\
\hline Al Abadi et al., [213] & 1992 & Eur Urol & 271 & $>=24$ & $<0.015$ & FCM & T1-4 \\
\hline \multicolumn{8}{|l|}{ Oxford level 3b } \\
\hline Tribukait [110] & 1993 & Eur Urol & 309 & 176 & $<0.0001$ & ICM & \\
\hline Van den Ouden et al., [214] & 1993 & J Urol & 963 & 96 & 0.023 & FCM & Stages T1-T4 \\
\hline Di Silverio et al., [215] & 1992 & Eur Urol & 80 & $\bar{x} 60$ & $<0.005$ & FCM & Stage A-D \\
\hline Forsslund et al., [216] & 1992 & Cancer & 145 & 276 & $<0.001$ & ICM & Cytological grade \\
\hline Fordham et al., [217] & 1986 & Br J Surg & 72 & $6-144$ & $<0.001$ & FCM & $\mathrm{HT}$ in $73 \%$ \\
\hline \multicolumn{8}{|l|}{ Oxford level 4} \\
\hline Miller et al., [204] & 1991 & J Urol & 103 & $>60$ & $<0.001$ & FCM & Stage D2 \\
\hline \multicolumn{8}{|l|}{ After active surveillance } \\
\hline \multicolumn{8}{|l|}{ Oxford level 3b } \\
\hline Vesalainen et al., [169] & 1994 & Brit J Cancer & 106 & $\bar{x} 156$ & 0.02 & FCM & T1-2, M0 \\
\hline Tribukait et al., [110] & 1993 & Europ Urol & 287 & $\bar{x} 176$ & $<0.001$ & FCM & FNABs \\
\hline \multicolumn{8}{|l|}{ Oxford level 4} \\
\hline Tribukait et al., [218] & 1991 & Acta Oncol & 125 & 72 & n.n. & FCM & FNABs \\
\hline \multicolumn{8}{|l|}{ Oxford level 3b } \\
\hline \multicolumn{8}{|l|}{ After TUR } \\
\hline \multicolumn{8}{|l|}{ Oxford level 2b } \\
\hline Borre et al., [219] & 1998 & Prostate & 120 & $\overline{\mathrm{x}} 180$ & 0.024 & FCM & $96 \mathrm{WHO}$ low grades only \\
\hline
\end{tabular}


Böcking et al. Pathology Discovery 2014,

http://www.hoajonline.com/journals/pdf/2052-7896-2-7.pdf

doi: 10.7243/2052-7896-2-7

Table 6. Addition of indenpendent prognostic information to the Gleason-score. Bold p-values refer to Cox multivariate regression analysis.

\begin{tabular}{|c|c|c|c|c|c|c|c|c|}
\hline Authors & Year & Journal & $\begin{array}{l}\text { Number of } \\
\text { patients }\end{array}$ & $\begin{array}{l}\text { Months of } \\
\text { follow-up }\end{array}$ & $\begin{array}{l}\text { Significance } \\
\mathrm{p}\end{array}$ & $\begin{array}{l}\text { Flow/Image } \\
\text { cytometry }\end{array}$ & $\begin{array}{l}\text { Diagnosis/ } \\
\text { Prognosis }\end{array}$ & Comment \\
\hline \multicolumn{9}{|l|}{ After RPE } \\
\hline \multicolumn{9}{|l|}{ Oxford level 2b } \\
\hline Bantis et al., [175] & 2009 & Tumori & 112 & $\bar{x} 60$ & 0.001 & $\mathrm{ICM}$ & $\mathrm{P}$ & pT2a-c, pT3a \\
\hline Pretorius et al., [16] & 2009 & Cell Oncol & 186 & $\bar{x} 73.3$ & $<0.001$ & $\mathrm{ICM}$ & & GS 7 \\
\hline Ward et al., [198] & 2005 & BJU international & 816 & $\bar{x} 126.6$ & 0.008 & FCM & & pT3 only \\
\hline Bantis et al., [176] & 2005 & $\begin{array}{l}\text { J Exp Clin Cancer } \\
\text { Res }\end{array}$ & 70 & $\bar{x} 60$ & $<0.007$ & $\mathrm{ICM}$ & $\mathrm{P}$ & \\
\hline Deliveliotis et al., [177] & 2003 & World J Urol & 84 & $\bar{x} 45$ & 0.0074 & FCM & $\mathrm{P}$ & -- \\
\hline Amling et al., [178] & 1999 & J Urol & 106 & 120 & 0.002 & FCM & & $\begin{array}{l}\text { After external } \\
\text { radiation }\end{array}$ \\
\hline Ross et al., [225] & 1999 & Urology & 211 & 60 & $<0.001$ & $\mathrm{FCM}$ & $\mathrm{P}$ & $\begin{array}{l}\text { Prediction of } \\
\text { recurrence }\end{array}$ \\
\hline Blute et al., [222] & 1997 & Adult Urology & 2712 & $\begin{array}{l}\text { At primary } \\
\text { diagnosis }\end{array}$ & 0.005 & FCM & $\mathrm{D}$ & $\begin{array}{l}\text { Correlation with } \\
\text { positive margins }\end{array}$ \\
\hline Lerner et al., [181] & 1996 & J Urol & 904 & $\bar{x} 42$ & p 0.0089 & FCM & & $\mathrm{pT} 1, \mathrm{pT} 2$ \\
\hline Ross et al., [170] & 1994 & Cancer & 89 & $\bar{x} 31.2$ & 0.006 & $\mathrm{ICM}$ & $\mathrm{P}$ & $\begin{array}{l}\text { Metastases \& } \\
\text { recurrences x3 }\end{array}$ \\
\hline Blute et al., [185] & 1989 & J Urol & 315 & 96 & 0.0004 & FCM & $\mathrm{P}$ & Stages A, B \\
\hline Winkler at al., [186] & 1988 & Mayo Clin Proc & 91 & $\bar{x} 90$ & $<0.001$ & FCM & $\mathrm{P}$ & Low and high GS \\
\hline \multicolumn{9}{|l|}{ Oxford level 3b } \\
\hline Isharwal et al., [176] & 2009 & J Urol & 370 & 3 & $\begin{array}{l}\text { AUC-ROC } \\
+1,5 \%\end{array}$ & ICM & $\mathrm{D}$ & ECS \\
\hline Ross et al., [225] & 1999 & Am J Surg Pathol & 111 & $\bar{x} 27$ & 0.002 & $\mathrm{ICM}$ & $\mathrm{P}$ & Disease recurrence \\
\hline Di Silverio et al., [215] & 1996 & Europ Urol & 85 & $\bar{x} 35$ & 0.05 & FCM & $\mathrm{P}$ & -- \\
\hline Hawkins et al., [187] & 1995 & Urology & 894 & $\bar{x} 100$ & $<0.05$ & FCM & $\mathrm{P}$ & Partially HT \\
\hline Ross et al., [170] & 1994 & Mod Pathol & 56 & $\bar{x} 28.8$ & 0.0026 & $\mathrm{ICM}$ & $\mathrm{P}$ & -- \\
\hline Tinari et al., [203] & 1993 & Cancer & 81 & 84 & 0.0044 & FCM & $\mathrm{P}$ & Stages T1 - T4 \\
\hline Voges et al., [189] & 1993 & Eur Urol & 85 & 70 & 0.001 & $\mathrm{FCM}$ & & Time to recurrence \\
\hline Montgomery et al., [190] & 1990 & Arch Surg & 261 & 240 & 0.001 & $\mathrm{FCM}$ & $\mathrm{P}$ & $\begin{array}{l}\text { Progression \& cause } \\
\text { spec. survival }\end{array}$ \\
\hline Nativ et al., [184] & 1989 & Mayo Clin Proc & 38 & 94.8 & 0.002 & $\mathrm{FCM}$ & $\mathrm{P}$ & $\begin{array}{l}\text { GS low-grade } \\
\text { subgroup }\end{array}$ \\
\hline \multicolumn{9}{|l|}{ After TUR } \\
\hline \multicolumn{9}{|l|}{ Oxford level 3b } \\
\hline Nielsen et al., [226] & 1993 & APMIS & 79 & 120 & 0.0035 & $\mathrm{FCM}$ & $\mathrm{P}$ & $\begin{array}{l}\text { Grading acc. to } \\
\text { Shelley }\end{array}$ \\
\hline \multicolumn{9}{|l|}{ After external radiation } \\
\hline \multicolumn{9}{|l|}{ Oxford level 2b } \\
\hline Pollack et al., [205] & 2003 & J Clin Oncol & 149 & 108 & 0.03 & $\mathrm{ICM}$ & $\mathrm{P}$ & Survival \\
\hline \multicolumn{9}{|l|}{ Oxford level 3b } \\
\hline Song et al., [206] & 1992 & J Urol & 65 & $>120$ & $<0.0001$ & $\mathrm{ICM}$ & $\mathrm{P}$ & Mayo Grade \\
\hline \multicolumn{9}{|l|}{ After brachytherapy } \\
\hline \multicolumn{9}{|l|}{ Oxford level 2b } \\
\hline Stephensen et al., [207] & 1987 & Cancer Res & 82 & $\bar{x} 91.8$ & 0.0109 & FCM & & $\begin{array}{l}\text { Pelvic lymphnode } \\
\text { dissection, D1, N+ }\end{array}$ \\
\hline \multicolumn{9}{|l|}{ Oxford level 3b } \\
\hline Peters-Gee et al., [60] & 1992 & Cancer & 51 & $\overline{\mathrm{X}} 52$ & $<0.05$ & $\mathrm{ICM}$ & & -- \\
\hline \multicolumn{9}{|l|}{ After hormonal therapy } \\
\hline \multicolumn{9}{|l|}{ Oxford level 2b } \\
\hline Martinez-Jabaloyas et al., [199] & 2004 & Actas Urol Espan & 54 & 120 & 0.009 & $\mathrm{ICM}$ & $\mathrm{P}$ & $\begin{array}{l}\text { All with bone } \\
\text { metastases }\end{array}$ \\
\hline Martinez-Jabaloyas et al., [208] & 2002 & Urology & 127 & $>120$ & 0.031 & FCM & $\mathrm{P}$ & -- \\
\hline Oxford level 3b & & & & & & & & -- \\
\hline Pollack et al., [205] & 2003 & J Clin Oncol & 149 & $\bar{x} 96$ & 0.005 & $\mathrm{ICM}$ & $\mathrm{p}$ & $\begin{array}{l}\text { After external } \\
\text { radiation }\end{array}$ \\
\hline
\end{tabular}


Böcking et al. Pathology Discovery 2014,

http://www.hoajonline.com/journals/pdf/2052-7896-2-7.pdf

doi: $10.7243 / 2052-7896-2-7$

Continuation of Table 6 .

\begin{tabular}{|c|c|c|c|c|c|c|c|c|}
\hline Authors & Year & Journal & $\begin{array}{l}\text { Number of } \\
\text { patients }\end{array}$ & $\begin{array}{l}\text { Months of } \\
\text { follow-up }\end{array}$ & $\begin{array}{l}\text { Significance } \\
\text { p }\end{array}$ & $\begin{array}{l}\text { Flow/Image } \\
\text { cytometry }\end{array}$ & $\begin{array}{l}\text { Diagnosis/ } \\
\text { Prognosis }\end{array}$ & Comment \\
\hline Ahlgren et al., [210] & 1997 & Urology & 96 & 176 & 0.0004 & ICM & $\mathrm{P}$ & FNABs \\
\hline Forsslund et al., [211] & 1996 & Cancer & 334 & 360 & 0.001 & ICM & $\mathrm{P}$ & FNABs \\
\hline Vesalainen et al., [169] & 1994 & Br J Cancer & 101 & $\bar{x} 156$ & 0.058 & FCM & $\mathrm{P}$ & -- \\
\hline Di Silverio et al., [201] & 1992 & Eur Urol & 80 & $\bar{x} 60$ & $<0.05$ & FCM & $\mathrm{P}$ & -- \\
\hline Fordham et al., [217] & 1986 & Br J Surg & 72 & $6-144$ & $<0.001$ & FCM & $\mathrm{P}$ & $\begin{array}{l}\text { Ploidy + GS better } \\
\text { than GS alone }\end{array}$ \\
\hline \multicolumn{9}{|l|}{ After active surveillance } \\
\hline \multicolumn{9}{|l|}{ Oxford level 2b } \\
\hline Adolfsson et al., [197] & 1990 & J Urol & 146 & $\bar{x} 50$ & 0.018 & FCM & $\begin{array}{l}\text { Non-Pro- } \\
\text { gression }\end{array}$ & $\begin{array}{l}\text { FNABs. Therapy if } \\
\text { progressed }\end{array}$ \\
\hline \multicolumn{9}{|l|}{ After TUR } \\
\hline \multicolumn{9}{|l|}{ Oxford level 2b } \\
\hline Borre et al., [219] & 1998 & Prostate & 120 & $\bar{x} 180$ & 0.024 & FCM & $\mathrm{P}$ & $\begin{array}{l}96 \text { WHO low grades } \\
\text { only }\end{array}$ \\
\hline
\end{tabular}

Table 7. Correlation of DNA-ploidy with local recurrence or progress. Bold p-values refer to Cox multivariate regression analysis.

\begin{tabular}{|c|c|c|c|c|c|c|c|}
\hline Authors & Year & Journal & $\begin{array}{l}\text { Number of } \\
\text { patients }\end{array}$ & $\begin{array}{l}\text { Months of } \\
\text { follow-up }\end{array}$ & Significance & $\begin{array}{l}\text { Flow/Image } \\
\text { cytometry }\end{array}$ & Comment \\
\hline \multicolumn{8}{|l|}{ After RPE } \\
\hline \multicolumn{8}{|l|}{ Oxford level $2 b$} \\
\hline Ross et al., [225] & 1999 & Am J Surg Pathol & 111 & $\bar{x} 27$ & 0.002 & ICM & -- \\
\hline Ross et al., [170] & 1994 & Cancer & 89 & $\bar{x} 31.2$ & $<0.001$ & ICM & $3 \mathrm{x}$ more frequent \\
\hline Zincke et al., [182] & 1992 & Cancer & 370 & $\bar{x} 60$ & $<0.0001$ & FCM & Plus hormonal treatment \\
\hline Montgomery et al., [190] & 1990 & Arch Surg & 283 & $\overline{\mathrm{x}} 112.8$ & $<0.001$ & FCM & Stage B \\
\hline Winkler et al., [186] & 1988 & Mayo Clin and Foundation & 91 & $>60$ & $<0.0001$ & FCM & Stage D1 \\
\hline \multicolumn{8}{|l|}{ After hormonal therapy } \\
\hline \multicolumn{8}{|l|}{ Oxford level $2 b$} \\
\hline Eskelinen et al., [227] & 1991 & Eur Urol & 35 & $\bar{x} 187$ & 0.028 & FCM & $\mathrm{T} 1 / 2$ \\
\hline \multicolumn{8}{|l|}{ After Brachytherapy } \\
\hline \multicolumn{8}{|l|}{ Oxford level $2 b$} \\
\hline Keyes et al., [223] & 2013 & In J Rad Oncol Biol Phys & 94 & $\bar{x} 90$ & 0.011 & ICM & PSA recurrence \\
\hline
\end{tabular}

Table 8. Correlation of DNA-ploidy with occurrence of lymphnode- or bone metastases. Bold p-values refer to Cox multivariate regression analysis.

\begin{tabular}{|c|c|c|c|c|c|c|c|c|}
\hline Authors & Year & Journal & $\begin{array}{l}\text { Number of } \\
\text { patients }\end{array}$ & $\begin{array}{l}\text { Months of } \\
\text { follow-up }\end{array}$ & $\begin{array}{l}\text { Significance } \\
\mathbf{p}\end{array}$ & $\begin{array}{l}\text { Flow/Image } \\
\text { cytometry }\end{array}$ & $\begin{array}{l}\text { Lymph } \\
\text { nodes/ Bone }\end{array}$ & Remarks \\
\hline \multicolumn{9}{|l|}{ After RPE } \\
\hline \multicolumn{9}{|l|}{ Oxford level $2 b$} \\
\hline Ross et al., $[\mathbf{1 7 0}]$ & 1994 & Cancer & 89 & $\bar{x} 31.2$ & 0.006 & ICM & & -- \\
\hline Ross et al., [229] & 1993 & Cancer & 100 & At primary diagnosis & 0.0001 & ICM & L \& B & 71 after laparatomy \\
\hline Winkler et al., [186] & 1988 & Mayo Clin Rep & 91 & $\bar{x} 90$ & $<0.0001$ & FCM & $\mathrm{B}$ & D1 \\
\hline \multicolumn{9}{|l|}{ Oxford level 3b } \\
\hline Ross et al., [173] & 1994 & Mod Pathol & 56 & $\bar{x} 28.8$ & 0.0026 & ICM & $\mathrm{L}, \mathrm{B}$ & -- \\
\hline \multicolumn{9}{|l|}{ Oxford level 4} \\
\hline Tucci et al., [57] & 1994 & $\begin{array}{l}\text { Brazilian J Med } \\
\text { Biol Res }\end{array}$ & 28 & $\bar{x} 50$ & 0.03 & ICM & $\mathrm{B}$ & -- \\
\hline \multicolumn{9}{|c|}{ After hormonal therapy } \\
\hline \multicolumn{9}{|l|}{ Oxford level 3b } \\
\hline Tribukait [235] & 1993 & Eur Urol & 309 & 176 & $<0.0001$ & FCM & & -- \\
\hline Eskelinen et al., [227] & 1991 & Eur Urol & 91 & $\bar{x} 187$ & 0.0601 & FCM & Ln & -- \\
\hline
\end{tabular}


Böcking et al. Pathology Discovery 2014,

in radical prostatectomies. Five simulated punch biopsies had been taken per specimen. The risk of underestimation decreased from $60 \%$ with one biopsy to $5 \%$ with five investigated biopsies [231].

- 123 DNA-histograms from 48 men with prostatectomy due to cancers of unknown stage (mean 2,6) had been compared with those of six preoperative biopsies (diploid, non-diploid). In 34 men (71\%) DNA-ploidy in prostatectomies was correctly predicted as either diploid or nondiploid on biopsies. Under-estimation occurred mainly when only one or two biopsies were analyzed [232].

\section{Conclusions}

All twelve reviews on diagnostic or prognostic DNA-measurements in prostate cancer published so far are merely "narrative" and not systematic ones. Yet, they all conclude that DNA-ploidy is of either diagnostic or of prognostic value, without considering the methodologic quality of addressed papers.

\section{Shortcomings of published papers}

The most frequent cause for exclusion of papers $(n=32)$ was an inadequate study design (not enough patients: $<50$ ), mixture of different therapies, lacking therapeutic, clinical or follow-up information, selection of patients. In 13 publications DNA-measurements were methodologically insufficient (inadequate sampling or calibration, measurements of sections of different thickness, paucity of cells). Correlation with nondiagnostic or prognostic features $(n=25)$ and dealing with methodological aspects only $(n=24)$ cannot be criticized. Many scientists did not obey existing respective international and interdisciplinary methodological consensus reports [30,32-34], especially concerning problematical types of specimens (sections), missing performance standards ( $<300$ nuclei) and individual prognostic interpretation of data.

\section{Algorithms for DNA-grading of prostate cancer}

[52] have been the first to propose an objective alternative for grading prostate cancer malignancy based on DNA-measurements in cancer cells. Our group has published on "DNA-grading of prostatic carcinoma: Prognostic validity and reproducibility" [233]. Up to 1998 no standardized, internationally agreed algorithms existed, on how to derive prognostically different groups from DNA-histograms of prostate cancers. Each author individually defined at least two, up to five different categories. The only common aspect was that they all comprised a DNA-diploid category as the prognostically most favorable one. In 1998 and 2001 the European Society of Analytical Cellular Pathology (ESACP) "Taskforce on Standardization of Diagnostic DNA-Image Cytometry" has published a detailed proposal how to derive four prognostically relevant groups, resp. grades of malignancy, from DNA-measurements of malignant tumors: peridiploid, peritetraploid, $x$-ploid and multiploid [33,34] (Figure 1 and Table 1). Unfortunately, not many authors have adopted the respective standardized algorithms since then. Thus, their results concerning the prognostic validity of DNA-grading the malignancy of prostate cancer are hardly comparable. Nevertheless, the main, clinically relevant differentiation refers to DNA-diploidy vs. DNA-non diploidy. During tumor progression, peridiploid cancers primarily increase their rate of proliferation [64,234]. Later on during tumor progression, additional peritetraploid clones evolve [235]. Thus, concerning diploidy vs. non-diploidy, it is not relevant which c-value the peridiploid peak exactly has, but if there is a second peak at $4 c$ or elsewhere. According to $[\mathbf{2 1 0}, \mathbf{2 3 4}]$ a prognostically relevant proliferation rate $>5 \%$ can be stated in peridiploid DNA-histograms, supposed a reasonable number of $>1000$ of nuclei had been measured to obtain representative results [34].

\section{Diagnostic accuracy}

The fact that DNA-ploidy-parameters are able to nearly exclude cancer spread beyond the capsule as detected after radical prostatectomy significantly more precise than the Gleason-Score, has been proven in 8 level 1b studies [167-174], Table 3. Thus DNA-ploidy should additionally be taken into consideration, whenever organ confinement is a prerequisite for certain therapeutic strategies, like AS.

\section{Prognostic validity}

For untreated patients with early prostate cancer under Active Surveillance the following results have been published:

- Documented for 120 untreated patients in a multivariate level $2 b$ study the significant superior ability of DNA-ploidy over the histological WHO-grade to predict tumor-specific survival time [219].

- Proved in a multivariate level $1 \mathrm{~b}$-study with a statistically significant correlation of DNA-ploidy with recurrence-free survival time in 146 untreated patients in comparison with the cytological grade $[197,236]$.

- Proved for 106 untreated patients in a multivariate level $2 \mathrm{~b}$ study a statistically significant correlation of DNAploidy with overall survival time in comparison with the Gleason-score [169].

- Proved for 287 primary untreated patients in a multivariate level 2 b study significant correlation with overall survival time in comparison with the cytological grade $[\mathbf{2 3 5}, \mathbf{2 3 6}$. Brachytherapy is another standard treatment for organ confined prostate cancer. Patients that most likely reveal cancer spread beyond the capsule have to be excluded from this approach. Using core biopsy material, [223] could correctly predict the majority of failures and non-failures, while Gleason-score failed (Figure 3). DNA-diploid patients had a significantly lower rate of disease recurrence as compared with DNA-aneuploid patients. Thus, DNA-grading of prostate cancer malignancy can be used to further specify the inclusion criteria for brachytherapy.

The fact that DNA-ploidy-parameters could prove in 17 retrospective level $2 \mathrm{~b}$ studies to add significant prognostic 


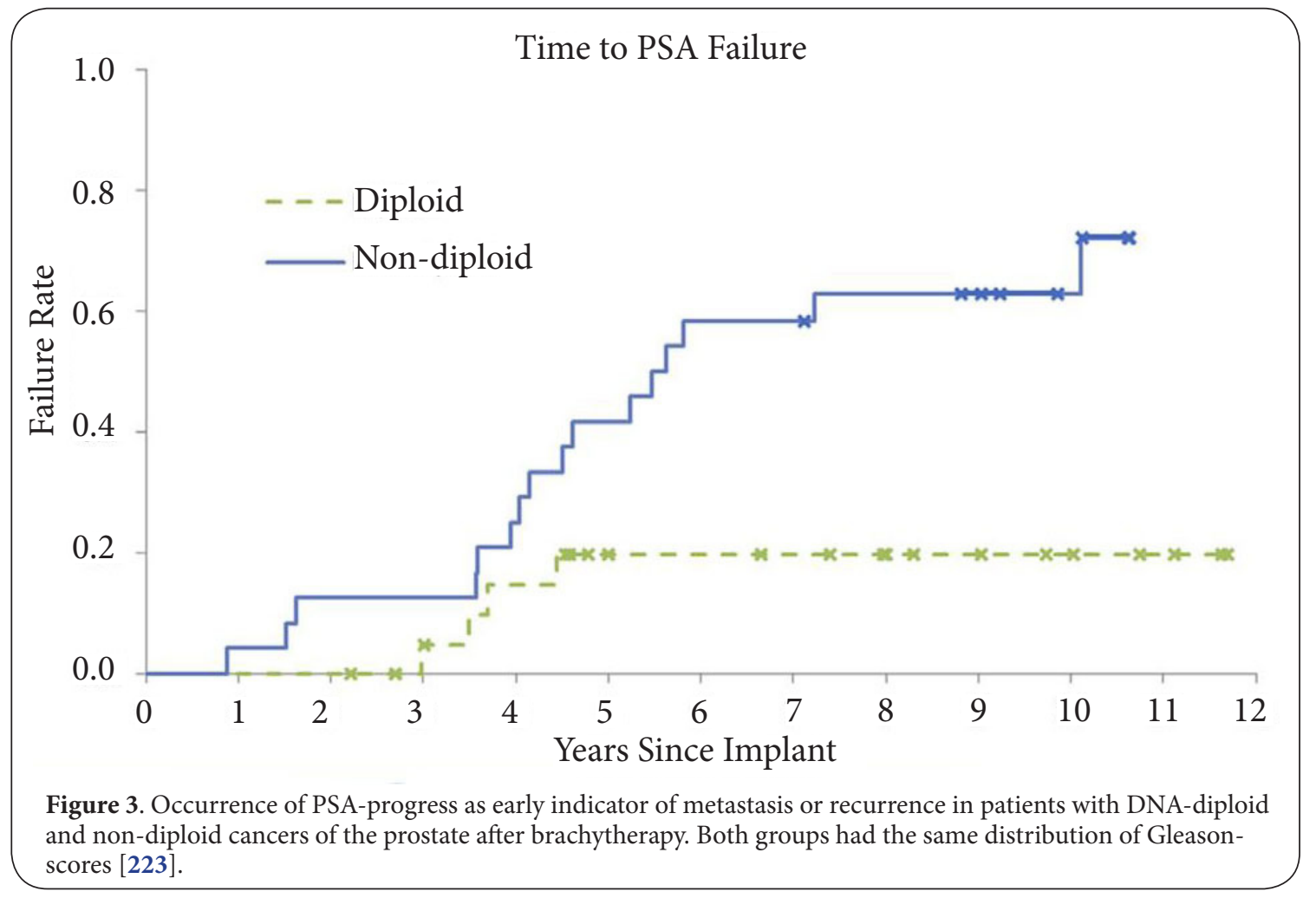

information to the Gleason-score independent from the type of therapy (Table 6) should encourage scientists to conduct studies in order to confirm these findings on a higher level of evidence as this had already been proposed by a WHOworking group [48]. Yet, level of evidence $1 \mathrm{~b}$ studies, proving independent prognostic validity of DNA-ploidy over Gleasonscore to predict non progression of clinically insignificant prostate cancers under Active Surveillance in a prospective setting are still missing. We recommend to perform these.

\section{Heterogeneity}

Data on the representativity of DNA-ploidy measurements on biopsies for the cancer as a whole are heterogeneous and depend on the number of samples investigated. While $[168,228]$ and [230] found discrepancies in only $3.8 \%, 5.0 \%$ and $8.0 \%$, $[210,232]$ reported different ploidy-levels in $24.1 \%$ and $29.0 \%$. These figures are lower than comparable ones for the Gleason-score (30\%:11). Because DNA-ploidy is inhomogenously distributed within prostate cancers, especially of advanced stages, as histopathological grades are, it is advisable to investigate all cancer foci in biopsies, either separately or pooled.

\section{Why is DNA-cytometry not used more widely?}

Some critical comments on this method overlook the enormous technological input that computer science, digital image analysis and informatics have meanwhile contributed to develop this method, becoming a biologically well founded, fast and valid prognostic technology. The fact that the procedure up to the recent development of digital nuclear classifiers has been too laborious and too time consuming and pathologists have not been sufficiently reimbursed, further prohibited its clinical acceptance.

While retrospective studies proving the independent prognostic validity of DNA-ploidy measurements have been published for all main types of treatment modalities of prostate cancers, prospective level $1 \mathrm{~b}$ studies are still missing. As no other treatment decision in cancers of the prostate is so much dependent from an objective, reproducible and valid prognostication of an individual cancers behavior as Active Surveillance, prospective studies should especially focus on patients under this strategy.

\section{Competing interests}

The authors declare that they have no competing interests.

\section{Authors' contributions}

\begin{tabular}{|l|c|c|c|c|c|}
\hline Authors' contributions & AB & MT & MS & JD & SB \\
\hline Research concept and design & $\checkmark$ & -- & -- & -- & -- \\
\hline Collection and/or assembly of data & -- & $\checkmark$ & $\checkmark$ & -- & -- \\
\hline Data analysis and interpretation & $\checkmark$ & -- & -- & $\checkmark$ & -- \\
\hline Writing the article & $\checkmark$ & -- & -- & -- & -- \\
\hline Critical revision of the article & -- & -- & $\checkmark$ & $\checkmark$ & $\checkmark$ \\
\hline Final approval of article & $\checkmark$ & -- & -- & -- & -- \\
\hline Statistical analysis & $\checkmark$ & -- & -- & -- & -- \\
\hline
\end{tabular}


Böcking et al. Pathology Discovery 2014,

http://www.hoajonline.com/journals/pdf/2052-7896-2-7.pdf

doi: 10.7243/2052-7896-2-7

\section{Publication history}

Senior Editor: Takuji Tanaka, Gifu University, Japan.

Received: 28-Aug-2014 Final Revised: 15-Sep-2014

Accepted: 03-Oct-2014 Published: 10-Oct-2014

\section{References}

1. Robert-Koch-Institut: Zentrum für Krebsregisterdaten. Krebsarten. 2013. | Website

2. Jemal A, Siegel R, Ward E, Murray T, Xu J, Smigal C and Thun MJ. Cancer statistics. CA Cancer J Clin. 2006; 56:106-30. | Article | PubMed

3. Schubert-Fritsche $G$, Eckel R, Eisenmenger $W$ and Hölzel D. Qualität von Angaben auf Todesbescheinigungen. Dtsch. Ärztebl. 2002; 99:A50-55. I Pdf

4. Weißbach, Lothar. New findings for treatment of locally confined prostate cancer. The HAROW-report 2014.

5. Stamatiou K, Alevizos A, Mariolis A, Spiliopoulou C, Alevizou A, Bovis K and Sofras F. Do clinically insignificant tumors of the prostate exist? Urol Int. 2008; 81:379-82. | Article | PubMed

6. Roemeling S, Roobol MJ, Postma R, Gosselaar C, van der Kwast TH, Bangma $\mathrm{CH}$ and Schroder FH. Management and survival of screendetected prostate cancer patients who might have been suitable for active surveillance. Eur Urol. 2006; 50:475-82. | Article | PubMed

7. Godtman RA, Holmberg E, Khatami A, Stranne J and Hugosson J. Outcome following active surveillance of men with screen-detected prostate cancer. Results from the Goteborg randomised populationbased prostate cancer screening trial. Eur Urol. 2013; 63:101-7. | Article | PubMed

8. Deutsche Gesellschaft für Urologie. Interdisziplinäre Leitlinie der Qualität S3 zur Früherkennung, Diagnose und Therapie der verschiedenen Stadien des Prostatakarzinoms. 2011, Version 2.0.

9. Epstein JI, Allsbrook WC, Jr., Amin MB and Egevad LL. The 2005 International Society of Urological Pathology (ISUP) Consensus Conference on Gleason Grading of Prostatic Carcinoma. Am J Surg Pathol. 2005; 29:1228-42. | Article | PubMed

10. Gleason DF and Mellinger GT. The Veterans Administration Cooperative Urological Research Group: Prediction of prognosis for prostatic adenocarcinoma by combined histological grading and clinical staging. J. Urol. 1974; 111:58-64.

11. Veloso SG, Lima MF, Salles PG, Berenstein CK, Scalon JD and Bambirra EA. Interobserver agreement of Gleason score and modified Gleason score in needle biopsy and in surgical specimen of prostate cancer. Int Braz J Urol. 2007; 33:639-46. | Article | PubMed

12. Burchardt $\mathrm{M}$, Engers R, Muller M, Burchardt T, Willers R, Epstein JI, Ackermann R, Gabbert HE, de la Taille $A$ and Rubin MA. Interobserver reproducibility of Gleason grading: evaluation using prostate cancer tissue microarrays. J Cancer Res Clin Oncol. 2008; 134:1071-8. | Article I PubMed

13. Netto GJ, Eisenberger $M$ and Epstein JI. Interobserver variability in histologic evaluation of radical prostatectomy between central and local pathologists: findings of TAX 3501 multinational clinical trial. Urology. 2011; 77:1155-60. | Article | PubMed Abstract | PubMed Full Text

14. Bottke D, Golz R, Störkel S, Hinke A, Siegmann A, Hertle L, Miller K, Hinkelbein $W$ and Wiegel T. Phase 3 study of adjuvant radiotherapy versus wait and see in $\mathrm{pT} 3$ prostate cancer: impact of pathology review on analysis. Eur Urol. 2013; 64:193-8. | Article | PubMed

15. Helpap B and Egevad L. The significance of modified Gleason grading of prostatic carcinoma in biopsy and radical prostatectomy specimens. Virchows Arch. 2006; 449:622-7. | Article | PubMed

16. Pretorius ME, Waehre H, Abeler VM, Davidson B, Vlatkovic L, Lothe RA, Giercksky KE and Danielsen HE. Large scale genomic instability as an additive prognostic marker in early prostate cancer. Cell Oncol. 2009; 31:251-9. | Article | PubMed

17. Billis A, Guimaraes MS, Freitas LL, Meirelles L, Magna LA and Ferreira U.
The impact of the 2005 International Society of Urological Pathology Consensus Conference on standard Gleason grading of prostatic carcinoma in needle biopsies. J Urol. 2008; 180:548-52. | Article | PubMed

18. Mitelman F, Johansson B and Mertens F (Eds.): Mitelman Database of Chromosome Aberrations and Gene Fusions in Cancer (2014). Cancer genome anatomy project. 2014.

19. Baretton GB, Valina C, Vogt $\mathrm{T}$, Schneiderbanger K, Diebold J and Lohrs $\mathrm{U}$. Interphase cytogenetic analysis of prostatic carcinomas by use of nonisotopic in situ hybridization. Cancer Res. 1994; 54:4472-80. Article | PubMed

20. Gburek BM, Kollmorgen TA, Qian J, D'Souza-Gburek SM, Lieber MM and Jenkins RB. Chromosomal anomalies in stage D1 prostate adenocarcinoma primary tumors and lymph node metastases detected by fluorescence in situ hybridization. J Urol. 1997; 157:223-7. | Article | PubMed

21. Alcaraz A, Takahashi S, Brown JA, Herath JF, Bergstralh EJ, LarsonKeller JJ, Lieber MM and Jenkins RB. Aneuploidy and aneusomy of chromosome 7 detected by fluorescence in situ hybridization are markers of poor prognosis in prostate cancer. Cancer Res. 1994; 54:3998-4002. | Article | PubMed

22. Henke RP, Kruger E, Ayhan N, Hubner D and Hammerer P. Frequency and distribution of numerical chromosomal aberrations in prostatic cancer. Hum Pathol. 1994; 25:476-84. | Article | PubMed

23. Matsuyama H, Pan $\mathrm{Y}$, Oba K, Yoshihiro S, Matsuda K, Hagarth L, Kudren D, Naito K, Bergerheim US and Ekman P. The role of chromosome 8p22 deletion for predicting disease progression and pathological staging in prostate cancer. Aktuelle Urol. 2003; 34:247-9. | Article | PubMed

24. Duesberg P, Li R, Fabarius A and Hehlmann R. The chromosomal basis of cancer. Cell Oncol. 2005; 27:293-318. | Article | PubMed

25. Duesberg $P$ and McCormack A. Immortality of cancers: a consequence of inherent karyotypic variations and selections for autonomy. Cell Cycle. 2013; 12:783-802. | Article | PubMed Abstract | PubMed Full Text

26. Shankey TV, Kallioniemi OP, Koslowski JM, Lieber ML, Mayall BH, Miller $\mathrm{G}$ and Smith GJ. Consensus review of the clinical utility of DNA content cytometry in prostate cancer. Cytometry. 1993; 14:497-500. | Article | PubMed

27. Ormerod MG, Tribukait B and Giaretti W. Consensus report of the task force on standardisation of DNA flow cytometry in clinical pathology. DNA Flow Cytometry Task Force of the European Society for Analytical Cellular Pathology. Anal Cell Pathol. 1998; 17:103-10. | Article | PubMed

28. Sandritter W, Carl M and Ritter W. Cytophotometric measurements of the DNA content of human malignant tumors by means of the Feulgen reaction. Acta Cytol. 1966; 10:26-30. | PubMed

29. Brugal $G$ and Chassery JM. A new image-processing system designed for densitometry and pattern analysis of microscopic specimens. Histochemistry. 1977; 52:241-258.

30. Böcking, Giroud F and Reith A. Consensus report of the ESACP task force on standardization of diagnostic DNA image cytometry. European Society for Analytical Cellular Pathology. Anal Cell Pathol. 1995; 8:67-74. | PubMed

31. Bacus JW and Bacus JV. Quality control in image cytometry: DNA ploidy. J Cell Biochem Suppl. 1994; 19:153-64. | PubMed

32. Giroud F, Haroske G, Reith A and Bocking A. 1997 ESACP consensus report on diagnostic DNA image cytometry. Part II: Specific recommendations for quality assurance. European Society for Analytical Cellular Pathology. Anal Cell Pathol. 1998; 17:201-8. Article I PubMed

33. Haroske G, Giroud F, Reith A and Böcking A. 1997 ESACP consensus report on diagnostic DNA image cytometry. Part I: basic considerations and recommendations for preparation, measurement and interpretation. European Society for Analytical Cellular Pathology. Anal Cell Pathol. 1998; 17:189-200. | PubMed

34. Haroske G, Baak JP, Danielsen H, Giroud F, Gschwendtner A, Oberholzer 
Böcking et al. Pathology Discovery 2014,

M, Reith A, Spieler $P$ and Böcking $A$. Fourth updated ESACP consensus report on diagnostic DNA image cytometry. Anal Cell Pathol. 2001; 23:89-95. | PubMed

35. Feulgen R. Neue Wege zum biologisch-histologischen Studium der Zellkerne. a) Die Nuklealfärbung, ein mikrochemischer Nachweis der Thymonukleinsäure. b) Über das Vorkommen von nuklealem und anuklealem Chromatin. Ber. Ges. Physiol. 1924; 22:489-490.

36. Engelhardt M. Kinetiken des Prostata Spezifischen Antigens als Indikationsstellung zur Prostatabiopsie. Med. Diss. Univ. Düsseldorf, Germany, 2014.

37. Tils M. Häufigkeit von DNA-Ploidiemustern in Stanzbiopsien vom Prostatakarzinom. Med. Diss. Univ. Düsseldorf, Germany, 2014.

38. Buhmeida A, Pyrhonen S, Laato M and Collan Y. Prognostic factors in prostate cancer. Diagn Pathol. 2006; 1:4. | Article | PubMed Abstract | PubMed Full Text

39. Montironi R, Mazzucchelli R, Scarpelli M, Lopez-Beltran A, Mikuz G, Algaba F and Boccon-Gibod L. Prostate carcinoma II: prognostic factors in prostate needle biopsies. BJU Int. 2006; 97:492-7. | Article PubMed

40. Epstein Jl, Amin M, Boccon-Gibod L, Egevad L, Humphrey PA, Mikuz G, Newling D, Nilsson S, Sakr W, Srigley JR, Wheeler TM and Montironi R. Prognostic factors and reporting of prostate carcinoma in radical prostatectomy and pelvic lymphadenectomy specimens. Scand J Urol Nephrol Suppl. 2005; 34-63. | Article I PubMed

41. Ross JS, Jennings TA, Nazeer T, Sheehan CE, Fisher HA, Kauffman RA, Anwar $\mathrm{S}$ and Kallakury BV. Prognostic factors in prostate cancer. Am J Clin Pathol. 2003; 120 Suppl:S85-100. | Article | PubMed

42. Chakravarti A and Zhai GG. Molecular and genetic prognostic factors of prostate cancer. World J Urol. 2003; 21:265-74. I Article I PubMed

43. Mazzucchelli R, Lopez-Beltran A, Scarpelli M and Montironi R. Predictive factors in prostate needle biopsy. Pathologica. 2002; 94:331-7. | PubMed

44. Miller GJ, Brawer MK, Sakr WA, Thrasher JB and Townsend R. Prostate cancer: serum and tissue markers. Rev Urol. 2001; 3 Suppl 2:S11-9. | PubMed Abstract | PubMed Full Text

45. Bostwick DG, Grignon DJ, Hammond ME, Amin MB, Cohen M, Crawford D, Gospadarowicz M, Kaplan RS, Miller DS, Montironi R, Pajak TF, Pollack A, Srigley JR and Yarbro JW. Prognostic factors in prostate cancer. College of American Pathologists Consensus Statement 1999. Arch Pathol Lab Med. 2000; 124:995-1000. | Article | PubMed

46. Sakr WA and Grignon DJ. Prostate cancer: indicators of aggressiveness. Eur Urol. 1997; 32 Suppl 3:15-23. | PubMed

47. Mikuz G. Pathology of prostate cancer. Old problems and new facts. Adv Clin Path. 1997; 1:21-34. I Article I PubMed

48. Schröder F, Tribukait B, Böcking A, DeVere White R, Koss L, Lieber M, Stenkvist B and Zetterberg A. Clinical utility of cellular DNA measurements in prostate carcinoma. Consensus Conference on Diagnosis and Prognostic Parameters in Localized Prostate Cancer. Stockholm, Sweden, May 12-13, 1993. Scand J Urol Nephrol Suppl. 1994; 162:51-63. | PubMed

49. Lieber MM. DNA ploidy: early malignant lesions. J Cell Biochem Suppl. 1992; 16H:44-6. | Article | PubMed

50. Deitch $A D$ and deVere White RW. Flow cytometry as a predictive modality in prostate cancer. Hum Pathol. 1992; 23:352-9. | Article PubMed

51. Böcking A. Diagnostic DNA cytometry of prostatic cancer. Diagn. Oncol. 1992; 2:90-102.

52. Tavares AS, Costa J, de Carvalho A and Reis M. Tumour ploidy and prognosis in carcinomas of the bladder and prostate. Br J Cancer. 1966; 20:438-41. | Article | PubMed Abstract | PubMed Full Text

53. Phillips B, Ball C, Sackett D, Badenoch D, Straus S, Haynes B, Dawes M and Howick J. Oxford Center for Evidence Based Medicine. Levels of evidence. 2009. | Website

54. Abaza R, Diaz LK, Jr., Laskin WB and Pins MR. Prognostic value of DNA ploidy, bcl-2 and p53 in localized prostate adenocarcinoma incidentally discovered at transurethral prostatectomy. J Urol. 2006;
176:2701-5. | Article | PubMed

55. Moussa M, Song TY, Frei JV, Peers G and Chin JL. DNA cytometric proliferative index predicting organ confinement in clinical stage-B prostate cancer. Clin Invest Med. 1997; 20:119-26. | Article | PubMed

56. Romics I, Bocsi J, Bach D, Beutler W, Frang D and Kopper L. DNA content of prostatic cancer measured by flow cytometry in patients undergoing radical prostatectomy. Anticancer Res. 1995; 15:1131-4. | PubMed

57. Tucci Junior S, Blumenfeld W and Narayan P. Ploidy status correlates with outcome in stage B prostate adenocarcinoma. Braz J Med Biol Res. 1994; 27:25-32. | Article | PubMed

58. Babiarz J, Peters JM, Miles B and Crissman JD. Comparison of DNA content in primary and lymph node metastases in prostate adenocarcinoma. Anal Quant Cytol Histol. 1993; 15:158-64. | Article | PubMed

59. Yokogi $\mathrm{H}$, Mizutani $\mathrm{M}$ and Ishibe T. Flow cytometric DNA analysis of stage D2 prostatic carcinoma. Urol Int. 1991; 47:57-9. | Article | PubMed

60. Mclntire TL, Murphy WM, Coon JS, Chandler RW, Schwartz D, Conway S and Weinstein RS. The prognostic value of DNA ploidy combined with histologic substaging for incidental carcinoma of the prostate gland. Am J Clin Pathol. 1988; 89:370-3. | Article | PubMed

61. Lundberg S, Carstensen J and Rundquist I. DNA flow cytometry and histopathological grading of paraffin-embedded prostate biopsy specimens in a survival study. Cancer Res. 1987; 47:1973-7. | Article | PubMed

62. Frankfurt OS, Chin JL, Englander LS, Greco WR, Pontes JE and Rustum YM. Relationship between DNA ploidy, glandular differentiation, and tumor spread in human prostate cancer. Cancer Res. 1985; 45:141823. | Article | PubMed

63. Böcking A, Auffermann W, Jocham D, Contractor $H$ and Wohltmann D. DNA grading of malignancy and tumor regression in prostatic carcinoma under hormone therapy. Appl Pathol. 1985; 3:206-14. | PubMed

64. Ahlgren G, Falkmer U, Gadaleanu V and Abrahamsson PA. Evaluation of DNA ploidy combined with a cytometric proliferation index of imprints from core needle biopsies in prostate cancer. Eur Urol. 1999; 36:314-9. | Article | PubMed

65. Nordgren H, Nilsson S, Eklov S, Stattin P, Naining W, Heiden T, Bergkvist L, Karlberg L, Lundholm C, Harvig B and et al. Modal DNA values and estramustine-binding protein (EMBP) as prognostic markers in prostatic cancer. Acta Oncol. 1991; 30:211-4. | Article I PubMed

66. Peters-Gee JM, Miles BJ, Cerny JC, Gaba AR, Jacobsen G and Crissman JD. Prognostic significance of DNA quantitation in stage D1 prostate carcinoma with the use of image analysis. Cancer. 1992; 70:1159-65. | Pdf | PubMed

67. Visakorpi T, Kallioniemi OP, Paronen IY, Isola JJ, Heikkinen AI and Koivula TA. Flow cytometric analysis of DNA ploidy and S-phase fraction from prostatic carcinomas: implications for prognosis and response to endocrine therapy. Br J Cancer. 1991; 64:578-82. | Article | PubMed Abstract | PubMed Full Text

68. Haugen OA and Mjolnerod O. DNA-ploidy as prognostic factor in prostatic carcinoma. Int J Cancer. 1990; 45:224-8. | Article I PubMed

69. Borgmann V, al-Abadi $\mathrm{H}$ and Nagel R. Treatment of locally advanced prostatic carcinoma with LHRH analogues: cytological, DNAcytophotometrical, and clinical results. Am J Clin Oncol. 1988; 11 Suppl 1:S19-28. | $\underline{\text { Article | PubMed }}$

70. Azua J, Romeo P, Valle J and Azua J, Jr. Cytologic differentiation grade and malignancy DNA index in prostatic adenocarcinoma. Anal Quant Cytol Histol. 1997; 19:102-6. | Article I PubMed

71. Azua J, Romeo P, Valle J and Azua J, Jr. DNA quantification as a prognostic factor in prostatic adenocarcinoma. Anal Quant Cytol Histol. 1996; 18:330-6. | Article | PubMed

72. Al Abadi $\mathrm{H}$ and Nagel R. Clinical relevance of cytology and DNAcytometry in the therapy of patients with prostatic carcinoma. Verh. Dtsch. Ges. Zyt. 1995; 19:181-197. 
Böcking et al. Pathology Discovery 2014,

http://www.hoajonline.com/journals/pdf/2052-7896-2-7.pdf

doi: 10.7243/2052-7896-2-7

73. Al-Abadi $H$ and Nagel R. Nuclear DNA analysis: the relevance of ploidy, DNA heterogeneity and phases of the cell cycle in 329 patients with prostatic carcinoma. A study on a follow-up of eight years. Urol Int. 1990; 45:350-5. | Article | PubMed

74. Al Abadi $\mathrm{H}$ and Nagel R. Prognostische Bedeutung von Ploidie und proliferativer Aktivität beim lokal fortgeschrittenen Prostatakarzinom. Akt. Urol. 1988; 19:182-186. | Article

75. Paz-Bouza JI, Orfao A, Abad M, Ciudad J, Garcia MC, Lopez A and Bullon A. Transrectal fine needle aspiration biopsy of the prostate combining cytomorphologic, DNA ploidy status and cell cycle distribution studies. Pathol Res Pract. 1994; 190:682-9. | Article | PubMed

76. Furusato M, Allsbrook WC, Jr., Kato H, Takahashi H, Miyasaka Y, Nomura $\mathrm{K}$, Asano K, Ito T and Aizawa S. Flow cytometric analysis of prostatic carcinoma with and without bone marrow metastasis. Adv Exp Med Biol. 1992; 324:189-91. | PubMed

77. Humphrey PA, Walther PJ, Currin SM and Vollmer RT. Histologic grade, DNA ploidy, and intraglandular tumor extent as indicators of tumor progression of clinical stage B prostatic carcinoma. A direct comparison. Am J Surg Pathol. 1991; 15:1165-70. | Article | PubMed

78. Qian J, Bostwick DG, Iczkowski KA, Betre K, Wilson MJ, Le C and Sinha AA. Characterization of prostate cancer in needle biopsy by cathepsin B, cell proliferation and DNA ploidy. Anticancer Res. 2010; 30:719-25. | Article | PubMed

79. Lorenzato $\mathrm{M}$, Rey D, Durlach A, Bouttens D, Birembaut P and Staerman F. DNA image cytometry on biopsies can help the detection of localized Gleason 3+3 prostate cancers. J Urol. 2004; 172:1311-3. | Article | PubMed

80. Buhmeida A, Backman $\mathrm{H}$ and Collan $\mathrm{Y}$. DNA cytometry in diagnostic cytology of the prostate gland. Anticancer Res. 2002; 22:2397-402. PubMed

81. Greene DR, Taylor SR, Wheeler TM and Scardino PT. DNA ploidy by image analysis of individual foci of prostate cancer: a preliminary report. Cancer Res. 1991; 51:4084-9. | Article | PubMed

82. Zetterberg $A$ and Forsslund $G$. Ploidy level and tumor progression in prostatic carcinoma. Acta Oncol. 1991; 30:193-9. | Article | PubMed

83. Forsslund $G$ and Zetterberg $A$. Ploidy level determinations in highgrade and low-grade malignant variants of prostatic carcinoma. Cancer Res. 1990; 50:4281-5. | Article | PubMed

84. Adolfsson J and Tribukait B. Modal DNA-values in prostate cancer patients with deferred therapy or endocrine therapy. Acta Oncol. 1991; 30:209-10. | Article | PubMed

85. Muller JG, Demel S, Wirth MP, Manseck A, Frohmuller HG and Muller HA. DNA-ploidy, G2M-fractions and prognosis of stages $B$ and C prostate carcinoma. Virchows Arch. 1994; 424:647-51. | Article | PubMed

86. Montironi R, Scarpelli M, Galluzzi CM and Diamanti L. Aneuploidy and nuclear features of prostatic intraepithelial neoplasia (PIN). J Cell Biochem Suppl. 1992; 16H:47-53. | Article | PubMed

87. Wang N, Stenkvist BG and Tribukait B. Morphometry of nuclei of the normal and malignant prostate in relation to DNA ploidy. Anal Quant Cytol Histol. 1992; 14:210-6. | Article | PubMed

88. Epstein JI, Christensen WN, Steinberg GD and Carter HB. Comparison of DNA ploidy and nuclear size, shape and chromatin irregularity in tissue sections and smears of prostatic carcinoma. Anal Quant Cytol Histol. 1990; 12:352-8. | Article | PubMed

89. Montironi R, Scarpelli M, Sisti S, Braccischi A, Gusella P, Pisani E, Alberti $R$ and Mariuzzi GM. Quantitative analysis of prostatic intraepithelial neoplasia on tissue sections. Anal Quant Cytol Histol. 1990; 12:366-72. | Article | PubMed

90. Bibbo M, Galera-Davidson H, Dytch HE, Lerma-Puertas E, Bartels $\mathrm{PH}$ and Wied G. Quantitative contextual karyometry in prostate carcinoma. InKarr JP, Coffey DS, Gardner W (Eds.), Prognostic cytometry and cytopathology of prostate cancer 1989; 200-217.

91. Waehre H, Amellem O, Stenwig AE, Tvera K, Juul M, Pettersen EO and Fossa SD. Deoxyribonucleic acid cytometry and histological findings before and after 125iodine implantation of primary prostate cancer. J
Urol. 1992; 148:838-41. | Article | PubMed

92. Leistenschneider W and Nagel R. Cytological and DNAcytophotometric monitoring of the effect of therapy in conservatively treated prostatic carcinomas. Scand J Urol Nephrol Suppl. 1980; 55:197-204. | PubMed

93. Leistenschneider $W$ and Nagel R. Zellkern-DNA-Analyse an unbehandelten und behandelten Prostatakarzinomen mit ScanningEinzelzell-Zytophotometrie. Akt. Urol. 1979; 10:353-358.

94. Kjaer TB, Thommesen P, Frederiksen P and Bichel P. DNA content in cells aspirated from carcinoma of the prostate treated with oestrogenic compounds. Urol Res. 1979; 7:249-51. | Article | PubMed

95. O'Sullivan DC, Barrett DM, Colby TV, Lieber MM and Cupps RE. Effect of external beam radiotherapy on prostatic carcinoma DNA content as measured by static image cytometry. Eur Urol. 1992; 21:235-9. | PubMed

96. Hussain MH, Powell I, Zaki N, Maciorowski Z, Sakr W, KuKuruga M, Visscher D, Haas GP, Pontes JE and Ensley JF. Flow cytometric DNA analysis of fresh prostatic resections. Correlation with conventional prognostic parameters in patients with prostate cancer. Cancer. 1993; 72:3012-9. | PubMed

97. Amberson JB and Koss JG. Measurements of DNA as a prognostic factor in prostatic carcinoma. In Karr JP, Coffey DS, Gardner W, (Eds.), Prognostic cytometry and cytopathology of prostate cancer. 1989; 281-286.

98. Benson $\mathrm{MC}$, Ring $\mathrm{K}$ and Giella J. Flow cytometry in carcinoma of the prostate. Urol Clin North Am. 1990; 17:885-91. | Article | PubMed

99. Tribukait B, Ronstrom $L$ and Esposti PL. Quantitative and qualitative aspects of flow DNA measurements related to the cytologic grade in prostatic carcinoma. Anal Quant Cytol. 1983; 5:107-11. | Article | PubMed

100. Lo J, Kerns BJ, Amling CL, Robertson CN and Layfield LJ. Correlation of DNA ploidy and histologic diagnosis from prostate core-needle biopsies: is DNA ploidy more sensitive than histology for the diagnosis of carcinoma in small specimens? J Surg Oncol. 1996; 63:41-5. | PubMed

101. DeVere White R and Deitch AD. Classification of prostate cells by DNAflow cytometry. In Karr JP, Coffey DS, Gardner W (Eds.), Prognostic cytometry and cytopathology of prostate cancer 1989; 188-199.

102. Lee F, Badalament RA, Hu C, Bousho I and Tsodikov A. Prostate cancers detected during 5alpha-reductase inhibitor use are smaller, dedifferentiated, but confined when compared to controls. J Cancer. 2012; 3:122-8. | Article | PubMed Abstract | PubMed Full Text

103. Habib FK, Bissas A, Neill WA, Busuttil A and Chisholm GD. Flow cytometric analysis of cellular DNA in human prostate cancer: relationship to 5 alpha-reductase activity of the tissue. Urol Res. 1989; 17:239-43. | PubMed

104. Nativ O, Myers RP, Farrow GM, Therneau TM, Zincke $H$ and Lieber MM. Nuclear deoxyribonucleic acid ploidy and serum prostate specific antigen in operable prostatic adenocarcinoma. J Urol. 1990; 144:3036. | Article | PubMed

105. LeRiche JC, Bruchovsky N, Goldenberg SL and de Jong G. Flow cytometry in the cytological and clinical assessment of prostatic carcinoma. In Karr JP, Coffey DS, Gardner W (Eds.), Prognostic cytometry and cytopathology of prostate cancer. 1989; 254-259.

106. Dejter SW, Jr., Cunningham RE, Noguchi PD, Jones RV, Moul JW, McLeod DG and Lynch JH. Prognostic significance of DNA ploidy in carcinoma of prostate. Urology. 1989; 33:361-6. | Article | PubMed

107. Currin SM, Lee SE and Walther PJ. Flow cytometric analysis of comedocarcinoma of the prostate: an uncommon histopathological variant of prostatic adenocarcinoma. J Urol. 1988; 140:96-100. | Article | PubMed

108. Willumsen $\mathrm{H}$, Thorup J, Norgaard T and Hansen $\mathrm{OH}$. Nuclear DNA content in prostatic carcinoma measured by flow cytometry: a retrospective study on paraffin-embedded tissue. APMIS Suppl. 1988; 4:120-5. I PubMed

109. Ekman P, Svennerus K, Zetterberg A and Gustafsson JA. 
Böcking et al. Pathology Discovery 2014,

Cytophotometric DNA analysis and steroid receptor content in human prostatic carcinoma. Scand. J. Urol. Nephrol. 1981; 60Suppl:85-88.

110. Tribukait B. Tumor biology in diagnostic cytology: DNA cytometry in carcinomas of the bladder and prostate. Recent Results Cancer Res. 1993; 133:23-31. | Article | PubMed

111. Falkmer UG. Methodologic sources of errors in image and flow cytometric DNA assessments of the malignancy potential of prostatic carcinoma. Hum Pathol. 1992; 23:360-7. | Article | PubMed

112. Falkmer UG. Methodological aspects on flow and image cytometric nuclear DNA assessments in prostatic adenocarcinoma. Acta Oncol. 1991; 30:201-3. | Article | PubMed

113. Stenkvist $B$ and Johansson-Browen I. Image analysis cytology for DNA determination in breast and prostate cancer. Acta Oncol. 1991; 30:911-6. | Article | PubMed

114. Benson MC, Karp F and Tobin MS. Multiparametric flow cytometric analysis of prostate cancer. In Karr JP, Coffey DS, Gardner W (Eds.), Prognostic cytometry and cytopathology of prostate cancer. 1989; 243-253.

115. Coon JS and Weinstein RS. Cellular DNA content in archival, paraffinembedded prostate carcinoma specimens. In Karr JP, Coffey DS, Gardner (Eds.), Prognostic cytometry and cytopathology of prostate cancer. 1989; 218-229.

116. Freudenberg N, Guzman J, Maier A, Pfänder R and Korth K. Cytology and DNA-cytometry of carcinoma of the prostate. MD-GKB. 1989; 55:74-77.

117. Klein FA, Ratliff JE and White FK. DNA distribution patterns of prostatic tissue obtained at time of transurethral resection. Urology. 1988; 31:260-5. | Article | PubMed

118. Benson MC and Walsh PC. The application of flow cytometry to the assessment of tumor cell heterogeneity and the grading of human prostatic cancer: preliminary results. J Urol. 1986; 135:1194-8. | Article I PubMed

119. Seppelt U, Sprenger E and Hedderich J. Investigation of automated DNA diagnosis and grading of prostatic cancer. Anal Quant Cytol Histol. 1986; 8:152-7. | Article | PubMed

120. Schultz RE, Varello MA, Tsou KC, Wein AJ and Murphy JJ. Simultaneous flow cytometric deoxyribonucleic acid and acid phosphatase analysis of benign and malignant lesions of the prostate. J Urol. 1985; 134:1133-6. | Article | PubMed

121. Auer $G$ and Zetterberg $A$. The prognostic significance of nuclear DNA content in malignant tumors of breast, prostate, and cartilage. In Koss LG, Coleman DV (Eds.): Advances in Clinical Cytology 1984; 123-134.

122. Muntzing J. DNA determinations for prognosis and therapy control in prostatic cancer. Semin Oncol. 1983; 10:16-20. | PubMed

123. Leistenschneider $W$ and Nagel R. Einzelzellzytophotometrische Zellkern-DNS-Analysen beim behandelten, entdifferenzierten Prostatakarzinom und ihre klinische Bedeutung. Urologe A. 1983; 22:157-161.

124. Zimmerman A, Truss F, Blech M, Schröter W and Barth M. Bedeutung der Impulszytophotometrie für Diagnose und Prognose des Prostatakarzinoms. Urologe A. 1983; 22:151-156.

125. Lämmel A, Roters $\mathrm{M}$, Kastendieck $\mathrm{H}$ and Becker $\mathrm{H}$. Flußzytometrische Bestimmung von DNA-Verteilungsmustern in malignen und benignen Prostatatumoren. Urologe A. 1981; 20:400-404.

126. Ronström L, Tribukait B and Esposti PL. DNA pattern and cytological findings in fine-needle aspirates of untreated prostatic tumors. A flow-cytofluorometric study. Prostate. 1981; 2:79-88. | Article | PubMed

127. Tribukait B, Esposti PL and Ronström L. Tumour ploidy for characterization of prostatic carcinoma: flow-cytofluorometric DNA studies using aspiration biopsy material. Scand J Urol Nephrol Suppl. 1980; 55:59-64. | PubMed

128. Frederiksen P, Thommesen P, Kjaer TB and Bichel P. Flow cytometric DNA analysis in fine needle aspiration biopsies from patients with prostatic lesions. Diagnostic value and relation to clinical stages. Acta Pathol Microbiol Scand A. 1978; 86A:461-4. | Article | PubMed
129. Zimmerman A and Truss F. Vergleichende zytologische und impulszytophotometrische Untersuchungen an Prostatazellen. Urologe A. 1978; 17:391-394.

130. Bichel P, Frederiksen P, Kjaer T, Thommesen $\mathrm{P}$ and Vindelov LL. Flow microfluorometry and transrectal fine-needle biopsy in the classification of human prostatic carcinoma. Cancer. 1977; 40:1206-11. | Article | PubMed

131. Goerttler K, Ehemann V, Tschahargane C and Stoehr M. Monodispersal and deoxyribonucleic acid analysis of prostatic cell nuclei. J Histochem Cytochem. 1977; 25:560-4. | Article | PubMed

132. Sprenger $E$, Michaelis WE, Vogt-Schaden $M$ and Otto $C$. The significance of DNA flow-through fluorescence cytophotometry for the diagnosis of prostate carcinoma. Beitr Pathol. 1976; 159:292-8. | Article | PubMed

133. Zetterberg A and Esposti PL. Cytophotomeric DNA-analysis of aspirated cells from prostatic carcinoma. Acta Cytol. 1976; 20:46-57. | PubMed

134. Sprenger $E$, Volk $L$ and Michaelis WE. [The significance of nuclear DNA-measurements in the diagnosis of prostatic carcinomas (author's transl)]. Beitr Pathol. 1974; 153:370-8. | PubMed

135. Krause FS, Feil G, Bichler KH, Schrott KM, Akcetin ZY and Engehausen DG. Heterogeneity in prostate cancer: prostate specific antigen (PSA) and DNA cytophotometry. Anticancer Res. 2005; 25:1783-5. | Article | PubMed

136. Bahn DK, Silverman P, Lee F, Sr., Badalament R, Bahn ED and Rewcastle JC. In treating localized prostate cancer the efficacy of cryoablation is independent of DNA ploidy type. Technol Cancer Res Treat. 2004; 3:253-7. | Article | PubMed

137. Buhmeida A, Kuopio $T$ and Collan $Y$. Influence of sampling practices on the appearance of DNA image histograms of prostate cells in FNAB samples. Anal Cell Pathol. 1999; 18:95-102. I PubMed

138. Coetzee LJ, Layfield LJ, Hars V and Paulson DF. Proliferative index determination in prostatic carcinoma tissue: is there any additional prognostic value greater than that of Gleason score, ploidy and pathological stage? J Urol. 1997; 157:214-8. | Article | PubMed

139. Kugler A, Gross AJ, Zoller G, Hemmerlein B, Kallerhoff $M$ and Ringert $\mathrm{RH}$. [Influence of DNA ploidy and grading on survival in primary metastatic prostate carcinoma]. Urologe A. 1997; 36:138-42. | Article I PubMed

140. Konchuba AM, Schellhammer PF, Kolm P, Clements MA and Wright GL, Jr. Deoxyribonucleic acid cytometric analysis of prostate core biopsy specimens: relationship to serum prostate specific antigen and prostatic acid phosphatase, clinical stage and histopathology. J Urol. 1993; 150:115-9. | Article | PubMed

141. Jones EC, McNeal J, Bruchovsky N and de Jong G. DNA content in prostatic adenocarcinoma. A flow cytometry study of the predictive value of aneuploidy for tumor volume, percentage Gleason grade 4 and 5, and lymph node metastases. Cancer. 1990; 66:752-7. | Article | PubMed

142. Ritchie AW, Dorey F, Layfield LJ, Hannah J, Lovrekovich $\mathrm{H}$ and deKernion JB. Relationship of DNA content to conventional prognostic factors in clinically localised carcinoma of the prostate. Br J Urol. 1988; 62:24560. | Article | PubMed

143. Sengupta S, Cheville JC, Lohse CM, Zincke H, Myers RP, Riehle DL, Pankratz VS, Blute ML and Sebo TJ. Conventional assessment of needle biopsy specimens is more useful than digital image analysis of proliferation and DNA ploidy in prediction of positive surgical margins at radical prostatectomy. Urology. 2006; 68:94-8. | Article | PubMed

144. DiMarco DS, Blute ML, Zincke H, Cheville JC, Riehle DL, Lohse CM, Pankratz VS and Sebo TJ. Multivariate models to predict clinically important outcomes at prostatectomy for patients with organconfined disease and needle biopsy Gleason scores of 6 or less. Urol Oncol. 2003; 21:439-46. | Article | PubMed

145. Sebo TJ, Cheville JC, Riehle DL, Lohse CM, Pankratz VS, Myers RP, Blute $\mathrm{ML}$ and Zincke $\mathrm{H}$. Predicting prostate carcinoma volume and stage at radical prostatectomy by assessing needle biopsy specimens for 
Böcking et al. Pathology Discovery 2014,

http://www.hoajonline.com/journals/pdf/2052-7896-2-7.pdf

doi: $10.7243 / 2052-7896-2-7$

percent surface area and cores positive for carcinoma, perineural invasion, Gleason score, DNA ploidy and proliferation, and preoperative serum prostate specific antigen: a report of 454 cases. Cancer. 2001; 91:2196-204. | Article | PubMed

146. Ring KS, Karp FS, Olsson CA, O'Toole K, Bixon R and Benson MC. Flow cytometric analysis of localized adenocarcinoma of the prostate: the use of archival DNA analysis in conjunction with pathologica grading to predict clinical outcome following radical retropubic prostatectomy. Prostate. 1990; 17:155-64. | Article | PubMed

147. Seay TM, Blute ML and Zincke $H$. Long-term outcome in patients with pTxN+ adenocarcinoma of prostate treated with radical prostatectomy and early androgen ablation. J Urol. 1998; 159:357-64. | Article | PubMed

148. Milcent S, Lorenzato M, Enaschescu D, Enaschescu C, Birembaut P and Staerman. La ploïdie cellulaire: facteur prédictif de cancer de prostate localement avancé. Progr. Urol. 2007; 17:819-823.

149. Gundorova LV, Avtandilov GG, Saniev KB and Zairat'iants OV. [Morphometric diagnostics of the prostate precancer and cancer by examination of ploidy]. Arkh Patol. 2003; 65:46-50. | PubMed

150. Martinez Jabaloyas JM, Ruiz Cerda JL, Sanz Chinesta S, Jimenez A, Hernandez $\mathrm{M}$ and Jimenez Cruz JF. [Prognostic value of DNA ploidy in prostatic cancer]. Actas Urol Esp. 2001; 25:283-90. I Article I PubMed

151. Danielsen HE, Kildal $W$ and Sudbo J. [Digital image analysis in pathology--exemplified in prostatic cancer]. Tidsskr Nor Laegeforen. 2000; 120:479-88. | Article | PubMed

152. Ishikawa A. [The clinical usefulness of flow cytometric DNA analysis in prostatic cancer]. Hinyokika Kiyo. 1992; 38:665-70. | Article | PubMed

153. Piaton E, Bringuier PP, Devonec M, Seigneurin D and Perrin P. [Analysis of tumor DNA by flow cytometry on prostate cyto-aspiration product. Value of routine cytologic evaluation]. Pathol Biol (Paris). 1991; 39:182-4. | Article | PubMed

154. Piaton E, Bringuier PP, Seigneurin D, Perrin P and Devonec M. [Heterogeneity of nucleolar distribution in prostatic cancer. Comparison with the cytological grade and DNA content]. Bull Cancer. 1991; 78:935-41. | PubMed

155. Sahin AA, Ro JY, El-Naggar AK, Ordonez NG, Babaian RJ and Ayala AG. Pseudosarcomatous fibromyxoid tumor of the prostate. Am. J. Clin. Pathol. 1991; 96:253-258.

156. Howell LP and Teplitz RL. Papillary carcinoma of prostatic ductal origin: a cytologic case report with immunohistochemical and quantitative DNA correlation. Diagn Cytopathol. 1989; 5:211-6. | Article I PubMed

157. Leistenschneider W. Cytophotometric DNA analysis as indicator of therapeutic responsiveness. In: Karr JP,Coffey DS, Gardner W: Prognostic cytometry andcytopathology of prostate cancer. 1989; 266-280.

158. Lundgren R, Hartley-Asp B and Henriksson H. Fine needle biopsy as a method for following ploidy changes in the Dunning R-3327 rat prostate tumour. In Vivo. 1988; 2:313-6. | PubMed

159. Collins JM, Bagwell CB, Block NL, Claflin AJ, Irvin GL, 3rd, Pollack A and Stover B. Flow cytometric monitoring of $\mathbf{R} 3327$ rat prostate carcinoma. Invest Urol. 1981; 19:8-13. | Article | PubMed

160. Robertson CN and Paulson DF. DNA in radical prostatectomy specimens. Prognostic value of tumor ploidy. Acta Oncol. 1991; 30:205-7. | Article | PubMed

161. Nativ $O$ and Lieber MM. Prostatic carcinoma: Prognostic importance of static and flow cytometric nuclear DNA ploidy measurements. Am. Urol. Assoc. 1991; 23:178-183.

162. Sassi I, Mangili F, Sanvito F, Andreassi A and Cantaboni A. Reproducibility of FCM-DNA ploidy analysis in prostatic cancer: comparison between needle biopsy and surgical specimens. Anal Cell Pathol. 1993; 5:17-21. | Article | PubMed

163. Nagel $R$ and al Abadi $H$. The prognostic significance of ploidy and DNAheterogeneity in the primary diagnosis and monitoring of patients with locally advanced prostatic carcinoma. Scand J Urol Nephrol Suppl. 1991; 138:83-92. | Pdf | PubMed
164. Fossa SD, Berner A, Waehre H, Heiden T, Juul ME, van den Ouden $\mathrm{D}$, Pettersen EO, Wang $\mathrm{N}$ and Tribukait $\mathrm{B}$. DNA ploidy in cell nuclei from paraffin-embedded material--comparison of results from two laboratories. Cytometry. 1992; 13:395-403. I PubMed

165. Takai K, Goellner JR, Katzmann JA, Myers RP and Lieber MM. Static and flow DNA cytometry of prostatic adenocarcinoma. Studies of needle biopsy and radical prostatectomy specimens. J. Urol. Pathol. 1994; 2:39-47.

166. Gettman MT, Bergstralh EJ, Blute M, Zincke H and Bostwick DG. Prediction of patient outcome in pathologic stage T2 adenocarcinoma of the prostate: lack of significance for microvessel density analysis. Urology. 1998; 51:79-85. | Article | PubMed

167. Isharwal S, Miller MC, Epstein JI, Mangold LA, Humphreys E, Partin AW and Veltri RW. DNA Ploidy as surrogate for biopsy gleason score for preoperative organ versus nonorgan-confined prostate cancer prediction. Urology. 2009; 73:1092-7. | Article | PubMed Abstract | PubMed Full Text

168. Brinker DA, Ross JS, Tran TA, Jones DM and Epstein JI. Can ploidy of prostate carcinoma diagnosed on needle biopsy predict radical prostatectomy stage and grade? J Urol. 1999; 162:2036-9. | Article | PubMed

169. Vesalainen S, Nordling S, Lipponen P, Talja M and Syrjanen K. Progression and survival in prostatic adenocarcinoma: a comparison of clinical stage, Gleason grade, S-phase fraction and DNA ploidy. $\mathrm{Br}$ J Cancer. 1994; 70:309-14. | Article | PubMed Abstract | PubMed Full $\underline{\text { Text }}$

170. Ross JS, Figge $H$, Bui $H X$, del Rosario AD, Jennings TA, Rifkin MD and Fisher HA. Prediction of pathologic stage and postprostatectomy disease recurrence by DNA ploidy analysis of initial needle biopsy specimens of prostate cancer. Cancer. 1994; 74:2811-8. | PubMed

171. Greene DR, Rogers E, Wessels EC, Wheeler TM, Taylor SR, Santucci RA, Thompson TC and Scardino PT. Some small prostate cancers are nondiploid by nuclear image analysis: correlation of deoxyribonucleic acid ploidy status and pathological features. J Urol. 1994; 151:1301-7. | Article | PubMed

172. Haggman $M$, de la Torre $M$, Brandstedt S, Norlen BJ, Norberg $M$ and Busch C. Pre- and postoperative DNA ploidy patterns correlated to pTstage, histological grade and tumour volume in total prostatectomy specimens. Scand J Urol Nephrol. 1994; 28:59-66. | $\underline{\text { Article I PubMed }}$

173. Ross JS, Figge $H L$, Bui $H X$, del Rosario AD, Fisher HA, Nazeer $T$, Jennings $\mathrm{TA}$, Ingle $\mathrm{R}$ and Kim DN. E-cadherin expression in prostatic carcinoma biopsies: correlation with tumor grade, DNA content, pathologic stage, and clinical outcome. Mod Pathol. 1994; 7:835-41. | Article | PubMed

174. Badalament RA, O'Toole RV, Young DC and Drago JR. DNA ploidy and prostate-specific antigen as prognostic factors in clinically resectable prostate cancer. Cancer. 1991; 67:3014-23. | Pdf I PubMed

175. Bantis A, Patsouris E, Gonidi M, Kavantzas N, Tsipis A, Athanassiadou AM, Aggelonidou E and Athanassiadou P. Telomerase RNA expression and DNA ploidy as prognostic markers of prostate carcinomas. Tumori. 2009; 95:744-52. | Pdf | PubMed

176. Bantis A, Gonidi M, Athanassiades P, Tsolos C, Liossi A, Aggelonidou E, Athanassiadou AM, Petrakakou E and Athanassiadou P. Prognostic value of DNA analysis of prostate adenocarcinoma: correlation to clinicopathologic predictors. J Exp Clin Cancer Res. 2005; 24:273-8. | Pdf | PubMed

177. Deliveliotis C, Skolarikos A, Karayannis A, Tzelepis V, Trakas N, Alargof $E$ and Protogerou $V$. The prognostic value of $p 53$ and DNA ploidy following radical prostatectomy. World J Urol. 2003; 21:171-6. | Article PubMed

178. Amling CL, Lerner SE, Martin SK, Slezak JM, Blute ML and Zincke H. Deoxyribonucleic acid ploidy and serum prostate specific antigen predict outcome following salvage prostatectomy for radiation refractory prostate cancer. J Urol. 1999; 161:857-62. | Article | PubMed

179. Gettman MT, Pacelli A, Slezak J, Bergstralh EJ, Blute M, Zincke H and Bostwick DG. Role of microvessel density in predicting recurrence in 
pathologic Stage T3 prostatic adenocarcinoma. Urology. 1999; 54:47985. | Article | PubMed

180. Mora LB, Moscinski LC, Diaz JI, Blair P, Cantor AB and Pow-Sang JM. Stage B prostate cancer: Correlation of DNA ploidy analysis with histological and clinical parameters. Cancer Control. 1999; 6:587-591. | Pdf | PubMed

181. Lerner SE, Blute ML, Bergstralh EJ, Bostwick DG, Eickholt JT and Zincke $\mathrm{H}$. Analysis of risk factors for progression in patients with pathologically confined prostate cancers after radical retropubic prostatectomy. J Urol. 1996; 156:137-43. | Article | PubMed

182. Zincke H, Bergstralh EJ, Larson-Keller JJ, Farrow GM, Myers RP, Lieber MM, Barrett DM, Rife CC and Gonchoroff NJ. Stage D1 prostate cancer treated by radical prostatectomy and adjuvant hormonal treatment. Evidence for favorable survival in patients with DNA diploid tumors. Cancer. 1992; 70:311-23. | Article | PubMed

183. Wirth MP, Muller HA, Manseck A, Muller J and Frohmuller HG. Value of nuclear DNA ploidy patterns in patients with prostate cancer after radical prostatectomy. Eur Urol. 1991; 20:248-52. | PubMed

184. Nativ O, Winkler HZ, Raz Y, Therneau TM, Farrow GM, Myers RP, Zincke $\mathrm{H}$ and Lieber MM. Stage $\mathrm{C}$ prostatic adenocarcinoma: flow cytometric nuclear DNA ploidy analysis. Mayo Clin Proc. 1989; 64:911-9. | Article | PubMed

185. Blute ML, Nativ O, Zincke H, Farrow GM, Therneau T and Lieber MM. Pattern of failure after radical retropubic prostatectomy for clinically and pathologically localized adenocarcinoma of the prostate: influence of tumor deoxyribonucleic acid ploidy. J Urol. 1989; 142:1262-5. | Pdf | PubMed

186. Winkler HZ, Rainwater LM, Myers RP, Farrow GM, Therneau TM, Zincke $\mathrm{H}$ and Lieber MM. Stage D1 prostatic adenocarcinoma: significance of nuclear DNA ploidy patterns studied by flow cytometry. Mayo Clin Proc. 1988; 63:103-12. | Article | PubMed

187. Hawkins CA, Bergstralh EJ, Lieber MM and Zincke $H$. Influence of DNA ploidy and adjuvant treatment on progression and survival in patients with pathologic stage T3 (PT3) prostate cancer after radical retropubic prostatectomy. Urology. 1995; 46:356-64. | Article | PubMed

188. Carmichael MJ, Veltri RW, Partin AW, Miller MC, Walsh PC and Epstein JI. Deoxyribonucleic acid ploidy analysis as a predictor of recurrence following radical prostatectomy for stage T2 disease. J Urol. 1995; 153:1015-9. | Article | PubMed

189. Voges GE, Eigner EB, Ross W, Sussman H, Stockle M, Freiha FS and Stamey TA. Pathologic parameters and flow cytometric ploidy analysis in predicting recurrence in carcinoma of the prostate. Eur Urol. 1993; 24:132-9. | PubMed

190. Montgomery BT, Nativ O, Blute ML, Farrow GM, Myers RP, Zincke H, Therneau TM and Lieber MM. Stage B prostate adenocarcinoma. Flow cytometric nuclear DNA ploidy analysis. Arch Surg. 1990; 125:327-31. | Article | PubMed

191. Lee SE, Currin SM, Paulson DF and Walther PJ. Flow cytometric determination of ploidy in prostatic adenocarcinoma: a comparison with seminal vesicle involvement and histopathological grading as a predictor of clinical recurrence. J Urol. 1988; 140:769-74. | Article | PubMed

192. Veltri RW, Partin AW, Epstein JE, Marley GM, Miller CM, Singer DS, Patton KP, Criley SR and Coffey DS. Quantitative nuclear morphometry, Markovian texture descriptors, and DNA content captured on a CAS-200 Image analysis system, combined with PCNA and HER-2/neu immunohistochemistry for prediction of prostate cancer progression. J Cell Biochem Suppl. 1994; 19:249-58. I PubMed

193. Centeno BA, Zietman AL, Shipley WU, Sobczak ML, Shipley JW, Preffer $\mathrm{FI}$, Boyle BJ and Colvin RB. Flow cytometric analysis of DNA ploidy, percent S-phase fraction, and total proliferative fraction as prognostic indicators of local control and survival following radiation therapy for prostate carcinoma. Int J Radiat Oncol Biol Phys. 1994; 30:309-15. I Article | PubMed

194. Khoo VS, Pollack A, Cowen D, Joon DL, Patel N, Terry NH, Zagars GK, von Eschenbach AC, Meistrich ML and Troncoso P. Relationship of Ki-67 labeling index to DNA-ploidy, S-phase fraction, and outcome in prostate cancer treated with radiotherapy. Prostate. 1999; 41:166-72. | Article | PubMed

195. Pollack A, Zagars GK, el-Naggar AK, Gauwitz MD and Terry NH. Neardiploidy: a new prognostic factor for clinically localized prostate cancer treated with external beam radiation therapy. Cancer. 1994 73:1895-903. | Pdf | PubMed

196. Stege R, Tribukait B, Lundh B, Carlstrom K, Pousette A and Hasenson M. Quantitative estimation of tissue prostate specific antigen, deoxyribonucleic acid ploidy and cytological grade in fine needle aspiration biopsies for prognosis of hormonally treated prostatic carcinoma. J Urol. 1992; 148:833-7. | Article | PubMed

197. Adolfsson J and Tribukait B. Evaluation of tumor progression by repeated fine needle biopsies in prostate adenocarcinoma: modal deoxyribonucleic acid value and cytological differentiation. J Urol. 1990; 144:1408-10. | Article | PubMed

198. Ward JF, Slezak JM, Blute ML, Bergstralh EJ and Zincke H. Radical prostatectomy for clinically advanced (cT3) prostate cancer since the advent of prostate-specific antigen testing: 15-year outcome. BJU Int 2005; 95:751-6. | Article | PubMed

199. Martinez Jabaloyas JM, Jimenez Sanchez A, Ruiz Cerda JL, Sanz Chinesta $\mathrm{S}$, Sempere A and Jimenez Cruz JF. [Prognostic value of DNA ploidy and nuclear morphometry in metastatic prostate cancer]. Actas Urol Esp. 2004; 28:298-307. | Article | PubMed

200. Myers RP, Larson-Keller JJ, Bergstralh EJ, Zincke H, Oesterling JE and Lieber MM. Hormonal treatment at time of radical retropubic prostatectomy for stage D1 prostate cancer: results of long-term followup. J Urol. 1992; 147:910-5. | Article | PubMed

201. Di Silverio F, D’Eramo G, Caponera M, Persechino F, Eleuteri P, Cavallo D, De Vita $R$ and Forte D. The prognostic value of DNA content in patients with prostatic carcinoma. Eur Urol. 1992; 21 Suppl 1:92-5. | PubMed

202. Bratt O, Anderson H, Bak-Jensen E, Baldetorp B and Lundgren R. Metaphase cytogenetics and DNA flow cytometry with analysis of S-phase fraction in prostate cancer: influence on prognosis. Urology. 1996; 47:218-24. | Article | PubMed

203. Tinari N, Natoli C, Angelucci D, Tenaglia R, Fiorentino B, Di Stefano P, Amatetti C, Zezza A, Nicolai M and lacobelli S. DNA and S-phase fraction analysis by flow cytometry in prostate cancer. Clinicopathologic implications. Cancer. 1993; 71:1289-96. | Article | PubMed

204. Miller J, Horsfall DJ, Marshall VR, Rao DM and Leong SY. The prognostic value of deoxyribonucleic acid flow cytometric analysis in stage D2 prostatic carcinoma. J Urol. 1991; 145:1192-6. | Article | PubMed

205. Pollack A, Grignon DJ, Heydon KH, Hammond EH, Lawton CA, Mesic JB, Fu KK, Porter AT, Abrams RA and Shipley WU. Prostate cancer DNA ploidy and response to salvage hormone therapy after radiotherapy with or without short-term total androgen blockade: an analysis of RTOG 8610. J Clin Oncol. 2003; 21:1238-48. | Article | PubMed

206. Song J, Cheng WS, Cupps RE, Earle JD, Farrow GM and Lieber MM. Nuclear deoxyribonucleic acid content measured by static cytometry: important prognostic association for patients with clinically localized prostate carcinoma treated by external beam radiotherapy. J Urol. 1992; 147:794-7. | Article | PubMed

207. Stephenson RA, James BC, Gay H, Fair WR, Whitmore WF, Jr. and Melamed MR. Flow cytometry of prostate cancer: relationship of DNA content to survival. Cancer Res. 1987; 47:2504-7. | Article | PubMed

208. Martinez-Jabaloyas JM, Ruiz-Cerda JL, Hernandez M, Jimenez A and Jimenez-Cruz F. Prognostic value of DNA ploidy and nuclear morphometry in prostate cancer treated with androgen deprivation. Urology. 2002; 59:715-20. | Article | PubMed

209. Pollack A, Troncoso P, Zagars GK, von Eschenbach AC, Mak AC, Wu CS and Terry NH. The significance of DNA-ploidy and S-phase fraction in node-positive (stage D1) prostate cancer treated with androgen ablation. Prostate. 1997; 31:21-8. I Article I PubMed

210. Ahlgren G, Lindholm K, Falkmer U and Abrahamsson PA. A DNA cytometric proliferation index improves the value of the DNA ploidy pattern as a prognosticating tool in patients with carcinoma of the prostate. Urology. 1997; 50:379-84. | Article | PubMed 
Böcking et al. Pathology Discovery 2014,

211. Forsslund G, Nilsson B and Zetterberg A. Near tetraploid prostate carcinoma. Methodologic and prognostic aspects. Cancer. 1996; 78:1748-55. | Pdf | PubMed

212. Jorgensen T, Yogesan K, Skjorten F, Berner A, Tveter KJ and Danielsen $\mathrm{HE}$. Histopathological grading and DNA ploidy as prognostic markers in metastatic prostatic cancer. Br J Cancer. 1995; 71:1055-60. | Article | PubMed Abstract | PubMed Full Text

213. Al-Abadi $\mathrm{H}$ and Nagel R. Nuclear DNA analysis: DNA heterogeneity in the monitoring of patients with locally advanced prostatic carcinoma. Eur Urol. 1992; 22:303-10. | PubMed

214. Van den Ouden D, Tribukait B, Blom JH, Fossa SD, Kurth KH, ten Kate FJ, Heiden T, Wang N and Schroder FH. Deoxyribonucleic acid ploidy of core biopsies and metastatic lymph nodes of prostate cancer patients: impact on time to progression. The European Organization for Research and Treatment of Cancer Genitourinary Group. J Urol. 1993; 150:400-6. | PubMed

215. Di Silverio F, D’Eramo G, Buscarini M, Sciarra A, Casale P, Di Nicola S, Loreto A, Seccareccia F and De Vita R. DNA ploidy, Gleason score, pathological stage and serum PSA levels as predictors of diseasefree survival in C-D1 prostatic cancer patients submitted to radical retropubic prostatectomy. Eur Urol. 1996; 30:316-21. | PubMed

216. Forsslund G, Esposti PL, Nilsson B and Zetterberg A. The prognostic significance of nuclear DNA content in prostatic carcinoma. Cancer. 1992; 69:1432-9. | Article | PubMed

217. Fordham MV, Burdge AH, Matthews J, Williams G and Cooke T. Prostatic carcinoma cell DNA content measured by flow cytometry and its relation to clinical outcome. Br J Surg. 1986; 73:400-3. | Article | PubMed

218. Tribukait B. DNA flow cytometry in carcinoma of the prostate for diagnosis, prognosis and study of tumor biology. Acta Oncol. 1991; 30:187-92. | Article | PubMed

219. Borre M, Hoyer M, Nerstrom B and Overgaard J. DNA ploidy and survival of patients with clinically localized prostate cancer treated without intent to cure. Prostate. 1998; 36:244-9. | Article | PubMed

220. Tavares AS, Costa J and Maia JC. Correlation between ploidy and prognosis in prostatic carcinoma. J Urol. 1973; 109:676-9. | Article | PubMed

221. Martinez Jabaloyas JM, Jimenez Sanchez A, Ruiz Cerda JL, Sanz Chinesta $\mathrm{S}$, Sempere $A$ and Jimenez Cruz JF. [Prognostic value of DNA ploidy and nuclear morphometry in metastatic prostate cancer]. Actas Urol Esp. 2004; 28:298-307. | Article | PubMed

222. Blute ML, Bostwick DG, Bergstralh EJ, Slezak JM, Martin SK, Amling $\mathrm{CL}$ and Zincke $\mathrm{H}$. Anatomic site-specific positive margins in organconfined prostate cancer and its impact on outcome after radical prostatectomy. Urology. 1997; 50:733-9. | Article | PubMed

223. Keyes M, Macaulay C, Hayes M, Korbelik J, Morris WJ and Palcic B. DNA ploidy measured on archived pretreatment biopsy material may correlate with prostate-specific antigen recurrence after prostate brachytherapy. Int J Radiat Oncol Biol Phys. 2013; 86:829-34. | Article I PubMed

224. Isharwal S, Miller MC, Epstein JI, Mangold LA, Humphreys E, Partin AW and Veltri RW. DNA Ploidy as surrogate for biopsy Gleason score for preoperative organ versus nonorgan-confined prostate cancer prediction. Urology. 2009; 73:1092-7. | Article | PubMed Abstract | PubMed Full Text

225. Ross JS, Sheehan CE, Ambros RA, Nazeer T, Jennings TA, Kaufman RP, Jr., Fisher HA, Rifkin MD and Kallakury BV. Needle biopsy DNA ploidy status predicts grade shifting in prostate cancer. Am J Surg Pathol. 1999; 23:296-301. | Article | PubMed

226. Nielsen K, Overgaard J, Bentzen SM and Bruun E. Histological grade, DNA ploidy and mean nuclear volume as prognostic factors in prostatic cancer. APMIS. 1993; 101:614-20. | Article | PubMed

227. Eskelinen $M$, Lipponen $P$, Majapuro $R$, Syrjanen $K$ and Nordling S. DNA ploidy, $\mathrm{S}$ phase fraction and $\mathbf{G} 2$ fraction as prognostic determinants in prostatic adenocarcinoma. Eur Urol. 1991; 20:62-6. I Pdf | PubMed

228. O'Malley FP, Grignon DJ, Keeney M, Kerkvliet N and McLean C. DNA heterogeneity in prostatic adenocarcinoma. A DNA flow cytometric mapping study with whole organ sections of prostate. Cancer. 1993; 71:2797-802. | Article | PubMed

229. Ross JS, Nazeer T, Church K, Amato C, Figge H, Rifkin MD and Fisher HA. Contribution of HER-2/neu oncogene expression to tumor grade and DNA content analysis in the prediction of prostatic carcinoma metastasis. Cancer. 1993; 72:3020-8. | Article | PubMed

230. Leung CS, Zbieranowski I, Demers I and Murray D. DNA image cytometry of prostatic carcinoma: a comparison of needle core biopsy and subsequent prostatectomy specimens. Mod Pathol. 1994; 7:195-9. | Article | PubMed

231. Wang N, Wilkin C, Böcking A and Tribukait B. Evaluation of tumor heterogeneity of prostate carcinoma by flow- and image DNA cytometry and histopathological grading. Anal Cell Pathol. 2000; 20:49-62. | PubMed

232. Häggarth L, Auer G, Busch C, Norberg M, Haggman M and Egevad L. The significance of tumor heterogeneity for prediction of DNA ploidy of prostate cancer. Scand J Urol Nephrol. 2005; 39:387-92. | Article | PubMed

233. Böcking A, Chatelain R, Orthen U, Gien G, von Kalckreuth G, Jocham D and Wohltmann D. DNA-grading of prostatic carcinoma: prognostic validity and reproducibility. Anticancer Res. 1988; 8:129-35. | PubMed

234. Tribukait $B$. Klinische Bedeutung der DNA-Durchflusszytometrie beim Prostatakarzinom. In: Samsel W und Böcking A (Eds.), Prognostische und therapeutische Bedeutung der DNA-Zytometrie beim Prostatakarzinom.Schriftenreihe zur Gesundheitsanalyse 2006, Gmünder Ersatzkasse, 41:115-133.

235. Tribukait B. Nuclear deoxyribonucleic acid determination in patients with prostate carcinomas: clinical research and application. Eur Urol. 1993; 23 Suppl 2:64-76. | PubMed

236. Esposti PL. Cytologic malignancy grading of prostatic carcinoma by transrectal aspiration biopsy. A five-year follow-up study of $\mathbf{4 6 9}$ hormone-treated patients. Scand J Urol Nephrol. 1971; 5:199-209. | Article | PubMed

\section{Citation:}

Böcking A, Tils M, Schramm M, Dietz J and Biesterfeld S. DNA-cytometric grading of prostate cancer systematic review with descriptive data analysis.

Pathol Discov. 2014; 2:7.

http://dx.doi.org/10.7243/2052-7896-2-7 